\title{
As formas cê(s) e você(s) na fala espontânea do PB: uma análise baseada em corpora
}

\author{
The $c \hat{e}(s)$ e você(s) forms in Brazilian Portuguese spontaneous speech: a corpus-based \\ analysis.
}

\begin{abstract}
RESUMO: O artigo apresenta uma proposta metodológica para a análise do processo de cliticização do pronome reduzido $c \hat{e}(s)$ em relação às formas dissilábicas ocê(s) e você( $(s)$. A hipótese é que todas as formas podem exercer funções diferentes, seja de sujeito ou de complemento preposicionado, ou seja, podem ser tônicas ou clíticas. Através da análise do corpus de fala espontânea CORAL-BRASIL foi possível identificar as ocorrências de uso da forma $c \hat{e}(s)$ em relação às outras, especialmente na função de sujeito, mas também na função de objeto preposicionado. A análise acústica permitiu verificar e confirmar algumas das hipóteses levantadas.
\end{abstract}

PALAVRAS-CHAVE: fala espontânea; pronomes de segunda pessoa; linguística de corpus; análise acústica; cliticização.

\begin{abstract}
This article presents a methodological proposal about the process of cliticization of the reduced pronoun $c \hat{e}(s)$ compared to the bisyllabic forms ocê(s)and você(s).Our hypothesis is that all the forms can play different functions, both as a subject and as a prepositional phrase, that is, can be stressed or clitic. By analysing the C-ORALBRASIL spontaneous speech corpus, it was possible to identify the used cases of the $c \hat{e}(s)$ form compared to the other forms, especially when used as a subject, but also when used as an indirect object. The acoustic analysis yerified and confirmed some of our assumptions.
\end{abstract}

KEYWORDS: spontaneous speech; secondperson pronouns; corpus linguistics; acoustic analysis; cliticization.

\section{Introdução}

Este artigo apresenta uma proposta metodológica inovadora para a análise do processo de cliticização do pronome reduzido $c \hat{e}(s)$ em relação às formas dissilábicas ocê( $(s)$ e você( $(s)$ e seus primeiros resultados.

As pesquisas sobre o fenômeno de redução do pronome você(s) têm sido amplamente debatidas no panorama linguístico do Português do Brasil (doravante PB). A maioria delas, contudo, é de cunho gerativista, como será discutido adiante. Tais pesquisas se desdobram sobre exemplos, às vezes pertencentes a corpora não muito especificados, às vezes criados pelos autores, e outras vezes produzidos em laboratório com falantes que lêem enunciados preparados ad hoc.

\footnotetext{
${ }^{*}$ Mestre em Linguística (UFMG), Doutoranda em Linguística (UFMG), Pesquisadora CAPES.
} 
A investigação apresentada neste artigo possui como novidade principal sua abordagem metodológica: os dados são retirados de um corpus de fala espontânea gravado em contexto natural, o corpus C-ORAL-BRASIL (RASO-MELLO, 2012) ${ }^{1}$. O corpus representa a diatopia mineira, é extremamente variado do ponto de vista diafásico e diastraticamente balanceado ${ }^{2}$. Entre os critérios de transcrição do corpus é especialmente importante para nossos fins a marcação das seis formas estudadas: $c \hat{e}(s)$, ocê(s) e você(s). Isso nos permite analisá-las no contexto em que foram pronunciadas por mais de 200 falantes diferentes. A qualidade acústica do corpus, apesar dele ser coletado em contexto natural, permite, na maioria dos casos, uma análise fonética confiável. Temos assim a possibilidade de combinar uma análise acústica de formas produzidas em contexto natural e em quantidades estatisticamente relevantes.

A tonicidade ou atonicidade de um pronome (assim como de qualquer item em contexto) é algo mensurável; em princípio não pode ser decidida com base na forma morfológica ou na posição sintática. Se isto foi feito até este momento é porque não existiam os instrumentos necessários para se observar diretamente as propriedades prosódicas dos pronomes em contexto natural. Iniciamos portanto o trabalho conferindo a tonicidade ou atonicidade dos pronomes através de uma análise acústica. Somente após ter identificado o que é tônico e o que é átono verificamos as diversas formas e as diferentes posições e funções a elas associadas.

O objetivo do estudo não foi adentrar-se na questão, já bastante discutida e que será abordada no próximo parágrafo, sobre se o pronome cê deve ser considerado um clítico pleno (VITRAL, 1996; RAMOS, 1997) um pronome fraco (PETERSEN, 2011) ou em processo de cliticização (VITRAL E RAMOS, 2008). O propósito é aqui apresentar dados extraídos em contexto natural e avaliados com base em critérios puramente fonéticos, antes de observá-los com base em sua posição sintática, procedimentos que serão detalhados no corpo do artigo.

\footnotetext{
${ }^{1}$ Naturalmente quando falamos em linguística de corpus, não nos referimos a um simples estudo baseado em dados reais como é tradição da sociolinguística variacionista laboviana. Estamos falando aqui da recentíssima disciplina de estudos sobre corpora que surge em anos recentes graças aos desenvolvimentos tecnológicos (SARDINHA, 2004; BIBER, 1988; SINCLAIR, 1987). Lembramos também que nesse estudo é utilizado um corpus de fala de terceira geração, ou seja, com o texto alinhado ao som e ao espectro acústico (veja-se a este respeito RASO, 2012a). Uma discussão aprofundada sobre a grande distância entre a linguística de corpus e a mais genérica noção de corpus como simples coleta de dados naturais é encontrada em Mello, 2012.

${ }^{2}$ RASO, 2012a.
} 


\section{Estado da arte}

O debate sobre o fenômeno de redução da forma você(s), passando pela forma ocê(s) até chegar em $c \hat{e}(s)$, originadas talvez da forma de tratamento Vossa Mercê, é alvo de debates há muito tempo. Não é aqui a sede para retomar esta discussão, mas quer-se fornecer um panorama básico para que possa ser melhor compreendida a novidade da proposta que será apresentada.

A maioria dos estudos feitos sobre o assunto é de cunho gerativista, e sustenta a hipótese de que a forma $c \hat{e}(s)$ seja um clítico. Segundo Vitral (1996) a forma cê não pode ocorrer nos ambientes em que ocê e você ocorrem, pois o comportamento sintático de cê é distinto. Sua hipótese é que a forma cê constitui uma etapa do processo de gramaticalização da forma Vossa Mercê. Segundo Vitral, a agramaticalidade de $c \hat{e}^{3}$ :

- como pronome preposto;

(a) * cê ele não viu.

- recebendo ênfase ou foco;

(b) * só cê tava mentindo.

- em ambiente objeto de preposição;

(c) * Eu falei pra $c \hat{e}$.

pode ser explicada pela natureza átona do pronome, pois esses são os ambientes das formas oblíquas tônicas.

Ramos (1997) efetua um estudo variacionista das formas você e cê. A autora analisa o fato de os jovens utilizarem a forma $c \hat{e}$ com referência menos definida, como em ${ }^{4}$ :

(d) cê pode visitar sempre esse local.

enquanto os mais idosos a utilizam com referência definida, como em:

(e) de que lado cê tá?

\footnotetext{
${ }^{3}$ Exemplos citados pelo autor.

${ }^{4}$ Exemplos da autora.
} 
Segundo Ramos, há uma tendência à especialização, mas não uma utilização categórica de nenhum dos dois usos, com referência definida ou indefinida. Isso seria índice de um processo de gramaticalização em curso.

Em estudos mais recentes, Vitral e Ramos (2006) trabalham com a noção de gramaticalização e defendem a teoria de que, no caso das formas cê(s)/ocê(s)/você(s), o processo de cliticização estaria em curso. A distribuição das três formas não é idêntica ${ }^{5}$ e o $c \hat{e}(s)$ estaria sujeito a certas restrições como:

- não poder aparecer topicalizado;

$$
\text { (f) * Cê ele não viu. }
$$

- não poder ser modificado por advérbio;

$$
\text { (g) Até * cê podia subir. }
$$

-não poder comparecer sozinho como resposta a uma questão;

$$
\begin{aligned}
& \text { (h) - Quem vai sair? } \\
& -{ }^{*} C \hat{e} \text {. }
\end{aligned}
$$

- não poder ser complemento de preposição,

(j) Eu faleu * pra cê...

- não poder comparecer em posição objeto;

$$
\text { (k) Eu amo* cê. }
$$

e não poder ser coordenado com uma forma tônica

$$
\text { (l) Ele } \mathrm{e} * c \hat{e} \text { podem votar contra. }
$$

Segundo Vitral e Ramos, os exemplos mostram a existência de uma complementariedade na distribuição, pois a forma cê, à exceção da posição de sujeito, não pode ocorrer nos ambientes em que as formas ocê e você ocorrem.

Finalmente, os autores afirmam que a forma cê não deve ser entendida como um clítico como os pronomes pessoais átonos das línguas românicas, mas uma forma em processo de cliticização.

\footnotetext{
${ }^{5}$ Veja-se Vitral e Ramos, 2006, p. 31 e seguintes.
} 
Petersen (2008) rediscute a classificação de Vitral e Ramos, de que cê(s) seria um clítico. Seguindo a teoria da tripartição pronominal de Cardinaletti e Starke (1999), a pesquisadora afirma que o que seus antecessores provaram é somente que $c \hat{e}(s)$ não é um pronome forte. Ela indica que é possível que o $c \hat{e}(s)$ seja complemento de preposição como em:

(m) Eu disse isso p'cê ontem.

(n) Quer que eu vá $c^{\prime} c e ̂$ lá. ${ }^{6}$

Isso, todavia, ocorre somente quando há uma "reestruturação prosódica da fala"7 , quando não há pausa entre os dois elementos fonéticos. Sua teoria é de que essa forma represente não um pronome clítico, mas um pronome fraco.

Em uma réplica às críticas levantadas por Petersen, Vitral e Ramos (2008) retomam sua teoria de base sobre a cliticidade da forma $c \hat{e}(s)$, afirmando que essa forma é morfofonologicamente reduzida. Segundo os estudiosos, a possibilidade de que cê(s) compareça como complemento de preposição é forçada e mereceria uma análise acústica. Além disso, é afirmado que a sequência cê seguido de verbo é "quase categórica" 8 segundo os resultados de vários estudos quantitativos.

Finalmente, a posição mais recente, de Othero (2013), questiona o processo de gramaticalização das três formas, afirmando que você e cê são dois pronomes distintos, e que a forma cê pode ser um pronome fraco ou um pronome pleno em processo de cliticização. O autor afirma que, do ponto de vista do comportamento prosódico, o cê não pode aparecer ao lado direito do grupo prosódico, pretônico, portanto, não pode ser sujeito posposto, complemento do verbo ou de preposição.

Muitos outros autores se ocuparam dessa questão, entre os quais citamos Ciríaco, Vitral e Reis (2004); Duarte (1986); Galves (1993); Kato e Tarallo (1987); Kato (1999); Nascimento (2010); Perini (2002, 2010); Bagno (2011) entre outros. Aqui, quisemos expor as questões de fundo de quem se ocupa do fenômeno exposto para podermos apresentar nossa proposta.

\footnotetext{
${ }^{6}$ Exemplos citados pela autora.

${ }^{7}$ Veja-se Petersen, 2008, p.302-303.

${ }^{8}$ Vitral e Ramos, 2008, p. 404.
} 


\section{Originalidade da proposta}

Como foi dito acima, a inovação deste trabalho é a utilização da metodologia da linguística de corpora na investigação de dados produzidos de forma espontânea e em contexto natural. É possível, assim, observar o que é realmente pronunciado por falantes da diatopia mineira em contexto natural, com qual frequência, em qual posição e com quais restrições; e, dadas as características do corpus, é possível analizar foneticamente os dados. A hipótese inicial pressupunha que:

I) haveria uma frequência alta na produção da forma reduzida $c \hat{e}(s)$ em relação àquelas dissilábicas ocê(s) e você(s);

II) a forma $c \hat{e}(s)$ poderia ser encontrada em posições diferentes daquela pré-verbal com a função de sujeito;

III) uma análise acústica poderia revelar diferenças de duração da forma cê( $(s)$ nas diferentes posições e denunciar correlações entre duração e tonicidade ou atonicidade. Ou seja, a mesma forma segmental poderia ser tônica ou átona, dependendo da sua consistência prosódica.

A melhor forma de fazer uma análise que tenha como base a fala espontânea em contexto natural é a utilização de um corpus cuja arquitetura permita a exploração sistemática dessas características.

O corpus C-ORAL-BRASIL é um corpus de fala espontânea informal do PB com foco na diatopia mineira, comparável aos corpora C-ORAL-ROM (CRESTI-MONEGLIA, 2005) para italiano, português europeu, francês e espanhol. O corpus é constituído por 208.130 palavras distribuídas em 139 gravações. Essas são divididas entre um contexto familiar/privado (159.364 palavras) e um contexto público (48.766 palavras). Cada um dos contextos foi separado por tipologia interacional: um terço de diálogos, um terço de conversações (diálogos entre mais de dois falantes) e um terço de monólogos. Os textos foram transcritos em formato CHAT (MACWHINNEY, 2000), ao qual foi implementada a anotação de fronteiras prosódicas (MONEGLIA; CRESTI, 1997). As transcrições foram alinhadas ao áudio através do software WinPitch (MARTIN, 2005). A qualidade acústica é geralmente muito boa, graças ao uso de equipamentos de gravação de última geração ${ }^{9}$.

\footnotetext{
${ }^{9}$ A respeito da arquitetura do corpus e de todos os dados pormenorizados de sua criação veja-se o cap. 2 "O corpus C-ORAL-BRASIL" (RASO, 2012a).
} 
O corpus C-ORAL-BRASIL possui uma grande variação diafásica, que permite atingir uma "representação mais fiel do universo" (MONEGLIA 2005, p. 11 ${ }^{10}$ ) linguístico. Segundo Biber (1993) para itens frequentes, como boa parte dos pronomes, excertos de cerca de 1000 palavras fornecem uma amostragem suficientemente confiável. No caso do C-ORAL-BRASIL, os textos variam entre um mínimo de 700 até um máximo de 4500 palavras, com uma média de 1500 palavras por texto, constituindo, portanto, um total muito maior do que aquele considerado suficiente por Biber.

Esse corpus apresenta, portanto, uma grande variedade de ocorrências dos pronomes de segunda pessoa. Como foi dito acima, o sistema de transcrição utilizado assinala as diferentes formas $c \hat{e}(s) / o c \hat{e}(s) / v o c \hat{e}(s)$, de maneira que estas podem ser recuperadas automaticamente através de qualquer programa de busca.

A validação da transcrição foi realizada de forma dúplice: uma validação antes da revisão final do corpus e outra depois da revisão final das transcrições ${ }^{11}$. A porcentagem de erro relativo à transcrição das formas pronominais foi avaliada à parte como todos os fenômenos de transcrição não ortográfica; para às formas cê(s)/ocê(s)/você(s), a margem de erro observada foi de $1,08 \%$ na validação inicial, comprovando portanto a alta confiabilidade desse corpus para nossa pesquisa. Além disso, esse trabalho analisou e verificou acusticamente 678 enunciados que continham, pelo menos, uma das formas estudadas. Nessa amostra, foram encontradas somente duas ocorrências de erro de transcrição: uma em que a forma cê foi transcrita como ocê (bpubdl07-608 ${ }^{12}$ ) e outra com a forma cês transcrita como ocês (bfamcv18-66). Contudo, esses valores continuam sendo mínimos, pois correspondem a uma margem de erro de $0,29 \%$. Essa margem de erro é estatisticamente irrelevante. Na linguística de corpus, é considerado como mais que aceitável uma margem de erro aquém de $5 \%{ }^{13}$. A análise feita serviu de certa forma, como uma terceira validação do corpus, quanto a esse fenômeno específico.

\footnotetext{
${ }^{10}$ Tradução nossa.

${ }^{11}$ Para os critérios de transcrição, revisão e de validação do corpus, veja-se a seção5 do capítulo 4 "Transcrição e segmentação prosódica do corpus C-ORAL-BRASIL: critérios de implementação e validação" (MELLO et alii, 2012) e MELLO E RASO, 2010.

${ }^{12}$ A sigla se refere ao arquivo áudio-texto: neste caso contexto público, diálogo, número do arquivo e número do enunciado.

${ }^{13}$ Veja-se, a esse respeito, HEUVEL et alii, (2000; 2008) e SCHIEL et al. (2004).
} 


\section{Os dados}

Graças às características do corpus acima descrito, uma parte do trabalho pôde ser realizada utilizando um programa de busca gratuito, o AntConc ${ }^{14}$, de maneira semi-automática. Já a classificação das formas nas diferentes posições e funções teve que ser realizada manualmente, pois dependia da análise de cada ocorrência. Todos os dados coletados e divididos foram inseridos em planilhas do tipo Excel, juntamente aos dados relativos aos contextos de ocorrência, texto de origem, metadados dos falantes, e todo o tipo de anotação que o pesquisador considerasse útil para a análise.

\subsection{Ocorrências e porcentagens}

A varredura de todo o corpus na busca das formas cê(s)/ocê(s)/você(s) confirmou a hipótese inicial da forte presença da forma $c \hat{e}(s)$ na língua falada espontânea: foram encontradas 2262 ocorrências da forma $c \hat{e}(s)$, das quais 2137 no singular e 125 no plural; no caso da forma ocê(s), foram verificadas 312 ocorrências, 281 no singular e 31 no plural. A forma você(s) apresentou 351 ocorrências das quais 312 no singular e 39 no plural. A tabela 1 relaciona esses dados:

Tabela 1: Ocorrências das formas $c \hat{e}(s) / o c \hat{e}(s) / v o c \hat{e}(s)$ no corpus C-ORAL-BRASIL.

\begin{tabular}{|c|c|c|}
\hline FORMA & NÚMERO DE OCORR ÊNCIAS & TOTAL \\
\hline$c \hat{e}$ & 2137 & \multirow{2}{*}{2262} \\
\hline cês & 125 & \\
\hline ocê & 281 & \multirow{2}{*}{312} \\
\hline ocês & 31 & \\
\hline você & 312 & \multirow{2}{*}{351} \\
\hline vocês & 39 & \\
\hline
\end{tabular}

Em termos percentuais, pode-se perceber ainda melhor qual a superioridade da forma reduzida $c \hat{e}(S)$ em relação às outras. $\mathrm{O}$ gráfico 1 exemplifica bem isto.

\footnotetext{
${ }^{14}$ Disponível gratuitamente em http://www.antlab.sci.waseda.ac.jp/antconc index.html
} 


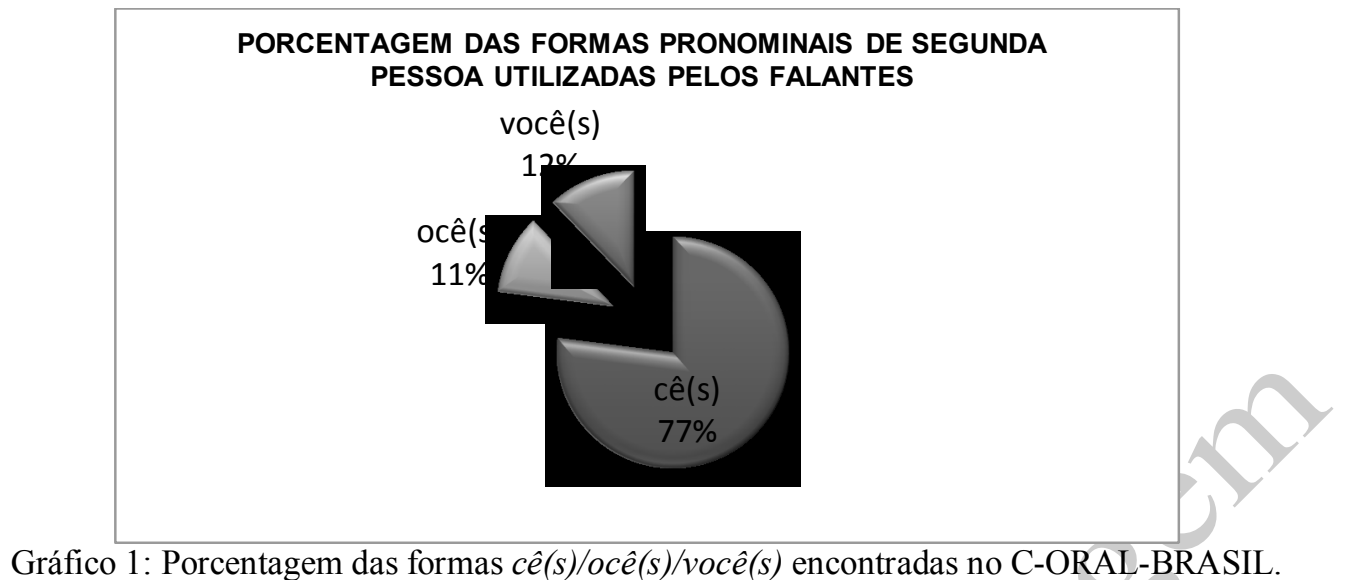

A forma mais utilizada pelos falantes gravados no C-ORAL-BRASIL, com 77\% das ocorrências foi $c \hat{e}(s)$. A forma você(s) compareceu em $12 \%$ dos casos, enquanto a forma ocê(s) teve frequência de $11 \%$.

Contudo, várias dessas ocorrências são, na verdade, formas que participam de disfluências do discurso; elas não possuem um valor semântico/sintático e, portanto, não devem entrar na análise.

Por disfluências entendemos aqueles casos em que há algum problema na execução da fala ou a fala é interrompida, seja por motivos externos, como a intervenção repentina de outro falante, ou por motivos internos ao falante. Os motivos internos podem ocorrer, por exemplo, quando o informante interrompe seu fluxo de fala porque não sabe como continuá-lo, podendo haver repetições da mesma palavra, ou para reformular seu pensamento e continuar o discurso com um plano diferente.

Os exemplos abaixo mostram casos de disfluência. O asterisco seguido de três letras maiúsculas indica o início de fala e a identificação do informante. A barra simples significa fronteira prosódica que delimita uma unidade tonal, e a barra dupla indica fronteira prosódica de final de enunciado. O símbolo “+” significa que o enunciado foi interrompido. A barra simples entre colchetes, seguida de um número, refere-se à quantidade de palavras anteriores que são idealmente canceladas pelo falante em um retracting ${ }^{15}$.

\footnotetext{
${ }^{15} \mathrm{~A}$ importância dessa anotação da segmentação prosódica da fala para os fins deste estudo será aprofundada na seção 4.2.5.
} 
(1)

*MAR: aí / c $\hat{\boldsymbol{e}}+$ depois que cê desfiou / (bfamdl11)

(2) *MAU: é que nem raspadinha // cê \&cum + o primeiro número que cê raspa / vem lá um prêmio bom // (bfamdl14)

(3) // cê [/1] a gente saiu / (bfamcv23)

(4) *BMR: aí depois / quando cê + no devedê / isso eu sei dum devedê / (bfamdl35)

Vejamos os dados na tabela 2 abaixo:

Tabela 2: Ocorrências das formas cê(s)/ocê(s)/você(s)em casos de disfluências.

\begin{tabular}{|c|c|c|c|}
\hline$\overline{\text { FORMA }}$ & TOTAL & EM DISFLUÊNCIA & Porcentagem dos casos de disfluência \\
\hline$c \hat{e}$ & 2137 & 116 & 5,43 \\
\hline$c \hat{e} S$ & 125 & 4 & 3,2 \\
\hline ocê & 281 & 17 & 6,04 \\
\hline ocês & 31 & 3 & 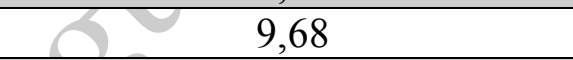 \\
\hline você & 312 & 13 & 4,17 \\
\hline vocês & 39 & 3 & $y=$ \\
\hline
\end{tabular}

Os casos de disfluências não são todos iguais. Seria oportuna uma análise mais atenta para verificar em quais casos se gera simplesmente uma multiplicação da mesma forma sem nenhum objetivo semântico/sintático (problema de execução da fala) e em quais casos a forma da disfluência preserva seu objetivo semântico/sintático. Contudo, para simplificar a análise, excluímos aqui todos os casos em que o pronome aparece em um enunciado não terminado, e quando o pronome é repetido por retracting, o contamos apenas uma vez. Retirando, portanto, as ocorrências de disfluências das formas $c \hat{e}(s) / o c \hat{e}(s) / v o c \hat{e}(s)$ há um novo quadro, ligeiramente diferente.

Tabela. 3: Ocorrências das formas $c \hat{e}(s) / o c \hat{e}(s) / \operatorname{voc} \hat{e}(s)$ excluindo-se as ocorrências de fenômenos de disfluências no corpus C-ORAL-BRASIL.

\begin{tabular}{|c|c|c|}
\hline FORMA & NÚMERO DE OCORRÊNCIAS & TOTAL \\
\hline$c \hat{\boldsymbol{e}}$ & 2021 & \multirow{2}{*}{2142} \\
\hline cếs & 121 & \\
\hline ocê & 264 & \multirow{2}{*}{292} \\
\hline ocês & 28 & \\
\hline você & 299 & \multirow{2}{*}{335} \\
\hline vocês & 36 & \\
\hline
\end{tabular}


O total de pronomes na forma $c \hat{e}(s)$ é agora de 2142, na forma ocê(s) de 292 e na forma você(s) 335. Em termos percentuais, isso significa que não há nenhuma mudança em relação à situação anterior: a forma $c \hat{e}(s)$ apresenta ainda $77 \%$ das ocorrências, a forma ocê(s) $11 \%$ das ocorrências e a forma você(s) $12 \%$.

\subsection{Distribuição}

A classificação das várias formas subdividiu os pronomes com base em sua posição, antes e depois do verbo. Em um segundo momento, foi verificada também a função sintática. Por se tratar de fala totalmente espontânea, há um certo número de ocorrências de sujeito posposto ao verbo; de enunciados em que o pronome se encontra em função contrastiva; de casos em que o pronome ocupa sozinho uma unidade tonal inteira, interna ao enunciado; e de casos em que o pronome ocupa uma unidade tonal inteira, mas que coincide também com o enunciado inteiro. Veremos depois a importância dessas últimas duas distribuições.

A tabela 4 abaixo exibe uma visão geral desses casos, que serão tratados de maneira pormenorizada a seguir.

Tabela. 4: Ocorrências das formas cê(s)/ocê(s)/você(s)nas diferentes posições no corpus C-ORAL-BRASIL.

\begin{tabular}{|c|c|c|c|c|c|c|}
\hline POSIÇÃ O & $c \hat{e}$ & $c \hat{e} s$ & ocê & ocês & você & vocês \\
\hline Pré-Verbal - Função Sujeito & 1955 & 120 & 173 & 11 & 207 & 17 \\
\hline Pós-Verbal - Função Sujeito & 0 & 0 & 11 & 0 & 11 & 2 \\
\hline Pós-Verbal - Função Objeto Direto & 0 & 0 & 12 & 3 & 5 & 4 \\
\hline $\begin{array}{c}\text { Pós-Verbal - Função Objeto } \\
\text { Preposicionado }\end{array}$ & 35 & 1 & 54 & 14 & 40 & 11 \\
\hline Pronome com função contrastiva & 0 & 0 & 2 & 0 & 6 & 0 \\
\hline $\begin{array}{c}\text { Pronome em isolamento na Unidade } \\
\text { Tonal }\end{array}$ & 29 & 1 & 12 & 0 & 21 & 1 \\
\hline Pronome em isolamento absoluto & 1 & 0 & 0 & 0 & 9 & 1 \\
\hline
\end{tabular}

Análises mais detalhadas serão comentadas adiante. Contudo, vale a pena ressaltar desde já alguns dados: em primeiro lugar, a alta incidência da forma $c \hat{e}(s)$ em posição pré-verbal e função de sujeito. Pode-se notar também sua total ausência na posição pós-verbal com função de objeto direto, confirmando, em dados de fala espontânea, o que foi encontrado na literatura com outros tipos de dados. Além disso, é interessante assinalar que a forma $c \hat{e}(s)$ não ocorre como sujeito posposto, em isolamento absoluto (ou seja, quando ocupa inteiramente o enunciado) ou em função contrastiva, o que também confirma o que a literatura sustenta. O que surpreende imediatamente, ao contrário, é que foram encontradas 36 ocorrências da forma em 
posição pós-verbal com função de objeto indireto, fato que toda a bibliografia consultada nega ser possível, e que, adiante, será comentado com maior detalhe.

\subsubsection{Posição pré-verbal}

A forma que prevalece em posição pré-verbal com função de sujeito é cê(s). Em posição pré-verbal, encontram-se $85 \%$ de $c \hat{e}(s)$, $7 \%$ de ocê(s) e $8 \%$ de você(s). Abaixo, exemplificamos tais ocorrências com alguns enunciados extraídos do corpus. A informação entre parênteses refere-se à identificação do texto do corpus da qual o exemplo foi extraído. Os números entre colchetes na transcrição, quando presentes, referem-se ao número do enunciado, atribuído automaticamente pelo programa WinPitch quando do alinhamento da transcrição com o áudio da gravação.

$C \hat{e}(s)$ :

(4) *RUT: [48] uai / e cê acha isso velho / <Terezinha> // (bfamcv02)

(6)// [186] cê nũ entendeu // (bfamcv03)

(7) [80] cês querem participar // (bfamcv01)

Ocê(s):

(8) *RUT: [269] uai / ocê nũ gostou <não / Jael> // (bfamcv02)

(9) *COZ: ocê que fica <no emeesseene> o dia todo / sô // (bpubd107)

(10) *LUZ: [335] ocês nũ acostumaram ainda // (bfamd103.txt)

$\operatorname{Voc} \hat{(s)}$ :

(11) *EVN: [111] hhh você está demitido // (bfamcv01)

(12) *MAE: pois é / mas ali você acha mais é malha // (bfamcv19)

(13) // então / vocês já conseguiram editar tudo // (bpubcv08.) 


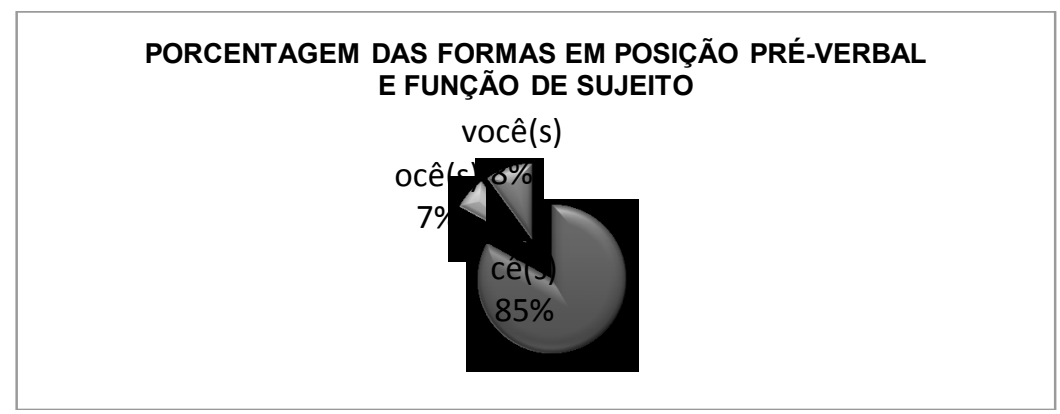

Gráfico. 2: Porcentagem das formas $c \hat{e}(s) / o c \hat{e}(s) / v o c \hat{e}(s)$ em posição pré-verbal e função de sujeito.

\subsubsection{Posição pós-verbal}

No caso das formas estudadas na posição pós-verbal, a situação é mais complexa, pois foram analisados três casos em que isso ocorre: quando a função sintática é de objeto direto, quando é de objeto preposicionado, e quando é de sujeito, nesse caso, posposto ao verbo.

Tabela. 5: Ocorrências das formas $c \hat{e}(s) / o c \hat{e}(s) / v o c \hat{e}(s)$ na posição pós-verbal em diferentes funções.

\begin{tabular}{|c|c|c|c|c|c|c|}
\hline POSIÇÃ O & $c \hat{e}$ & $c \hat{e}$ & $o c \hat{e}$ & $o c \hat{e}$ & você & vocês \\
\hline Pós-Verbal - Função Sujeito & 0 & 0 & 11 & 0 & 11 & 2 \\
\hline Pós-Verbal - Função Objeto Direto & 0 & 0 & 12 & 3 & 5 & 4 \\
\hline $\begin{array}{c}\text { Pós-Verbal - Função Objeto } \\
\text { Indireto }\end{array}$ & 35 & 1 & 54 & 14 & 40 & 11 \\
\hline
\end{tabular}

No caso da função de sujeito posposto, a forma $c \hat{e}(s)$ não apresentou nenhuma ocorrência, corroborando o relatado pela literatura, enquanto as formas ocê(s) e você(s) apresentaram, respectivamente, 11 e 13 ocorrências.

Exemplos de sujeito posposto:

(14 ) // Maria José / vai lá você / traz arroz pa frente / arroz e feijão // (bfamcv18)

(15) *TER: [70] conta ocê / Rute // (bfamcv02)

Pode-se observar que também a função de objeto direto é exercida somente pelas formas $o c \hat{e}(s)$ e você(s); não foi encontrada nenhuma ocorrência da forma $c \hat{e}(s)$, corroborando o que é afirmado pela literatura.

(16) // [97] falei / porque / ela / gerou você pra mim // (bfammn05) 
(17) *JOS: cadê $o c \hat{e}>/ /($ bfamcv05)

\subsubsection{Função de objeto preposicionado}

O estudo das formas $c \hat{e}(s) / o c \hat{e}(s) / v o c \hat{e}(s)$ na posição pós-verbal e na função de objeto preposicionado merece uma seção à parte, por contrariar quanto afirmado até agora pela literatura. Foram encontradas 68 ocorrências de ocê(s) nesta posição e função e 51 de você(s) A parte mais interessante contudo são as 35 ocorrências da forma cê no singular, e o único caso de cês no plural, presentes no corpus. Seguem alguns exemplos abaixo, com os respectivos arquivos de áudio.

(18)

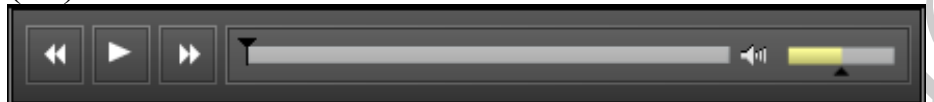

/ eu / nũ tenho preocupação com você lá fora // (bfammn24-53)

(19)

\begin{tabular}{|l|l|l|l|}
\hline$*$ & $\nabla$ & M & $\square$ \\
\hline
\end{tabular}

// falei c' ocê // (bfamd130-68)

(20)

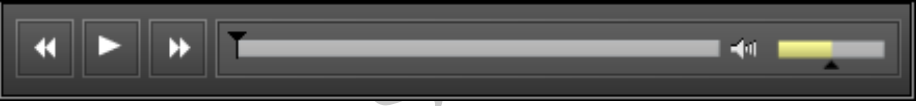

como é que foi esse projeto $p r^{\prime}$ ocê // (bpudl11-241)

$(21)$

"

*FLA: ranjar um dadinho $p^{\prime}$ ocê // (bfamcv21-50)

(22)

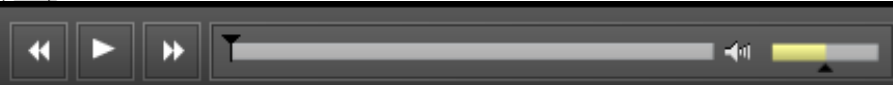

// [90] acho que ea fica melhor do que da outra // [91] $p^{\prime} c \hat{e} / /$ (bpud101-90-91)

(23)

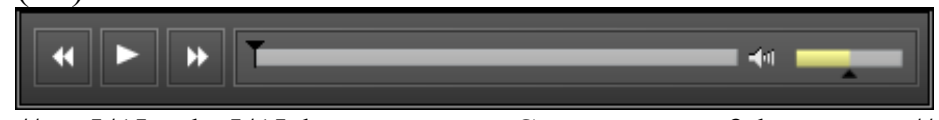

// e [/1] e lá [/1] lá em Lagoa Santa o xxx falou c’ cê // (bfamd117-201) 


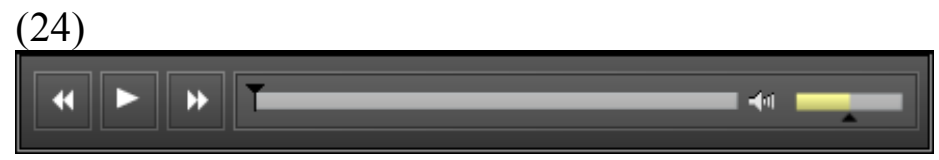

// eu já falei com cê / hein / paciência é uma virtude // (bfamdl12-21)

Se forem comparados os totais de objetos preposicionados em porcentagem verá-se que o $c \hat{e}(s)$ representa quase um quarto do total. Esse é um número muito alto, se considerarmos que, até agora, a literatura não incluía essa forma entre as possíveis nessa função. Graças à análise de dados espontâneos, pôde-se perceber que a forma não somente é possível, mas também bastante frequente.

\section{PORCENTAGEM DE OBJETOS PREPOSICIONADOS}

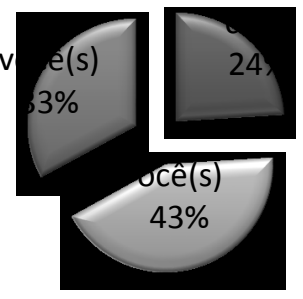

Gráfico. 3: Porcentagem das formas $c \hat{e}(s) / o c e ̂(s) / v o c e ̂(s)$ em posição pós-verbal e função de objeto preposicionado.

Quando consideramos as ocorrências somente no singular, pode-se notar que a ocorrência é ainda maior, e a presença da forma cê representa um percentual ainda mais alto.

PORCENTAGEM DE OBJETOS PREPOSICIONADOS

NO SINGULAR

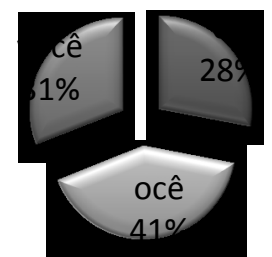

Gráfico. 4: Porcentagem das formas cê/ocê/você no singularem posição pós-verbal com função de objeto preposicionado.

Nesse caso, são detectáveis $41 \%$ dos casos na forma ocê, $31 \%$ na forma você e $28 \%$, quase um terço, na forma cê. 
É importante ressaltar que nas ocorrências encontradas as preposições que compareceram foram com (28 ocorrências e 78\% dos casos), c', contração de com (2 ocorrências e 5\% dos casos) e $p^{\prime}$, contração de para (6 ocorrências e 17\% dos casos) no singular. Com a forma plural a preposição utilizada é $d^{\prime}$, contração de $d e$.

O fato que não todas as preposições foram encontradas com a forma $c \hat{e}(s)$ pode ser motivo de discussão. Contudo devemos lembrar que o fato de que um corpus não apresente algumas formas não significa que elas não possam existir. A não presença de uma ou outra forma no corpus não pode ser um argumento para não explicar as formas presentes. $\mathrm{O}$ fato portanto que não apareça uma forma como pra cê é interessante, mas não pode ser utilizado como argumento para invalidar, de alguma forma, a presença de $p^{\prime}$ cê ou de com cê, etc.

Uma discussão de natureza diferente poderia envolver a confiabilidade das análises acústicas; por exemplo, poderia-se supor que as formas $p^{\prime} c \hat{e}$ e $c^{\prime} c \hat{e}$ sejam na realidade casos de formas p'ocê e c'ocê em que a vogal o está muito reduzida. Ou que a forma com cê poderia ser uma espécie de crase nasalizada em que há alongamento vocálico do õ que impossibilitaria a distinção entre o cê e o ocê. Abaixo estão os espectrogramas dos enunciados (18) a (24) em que é possível averiguar e comparar alguns casos de $p r$ 'ocê, $p^{\prime}$ ocê e $p^{\prime} c \hat{e}$, e aqueles de c'oce, com cê e c' cê. Apesar de todos os limites que apresenta o espectrograma de gravações em contexto natural, consegue-se perceber claramente, tanto à oitiva quanto examinando o espectrograma, a diferença que se passa entre os casos em que há o $o$, que seria evidenciado pela presença distinta de formantes vocálicos, daqueles em que este é ausente. Caso se possa admitir uma quantidade mínima de elemento vocálico, o que aqui contudo não é admitido, isto seria algo bastante natural na fonologia do $\mathrm{PB}$, entre uma oclusiva e uma sibilante, como ocorre na pronúncia da palavra $p(i)$ siquiatra. Isto justificaria uma pequena epêntesi vocálica, que todavia não foi encontrada no estudo.

Vejamos portanto os espectrogramas: 

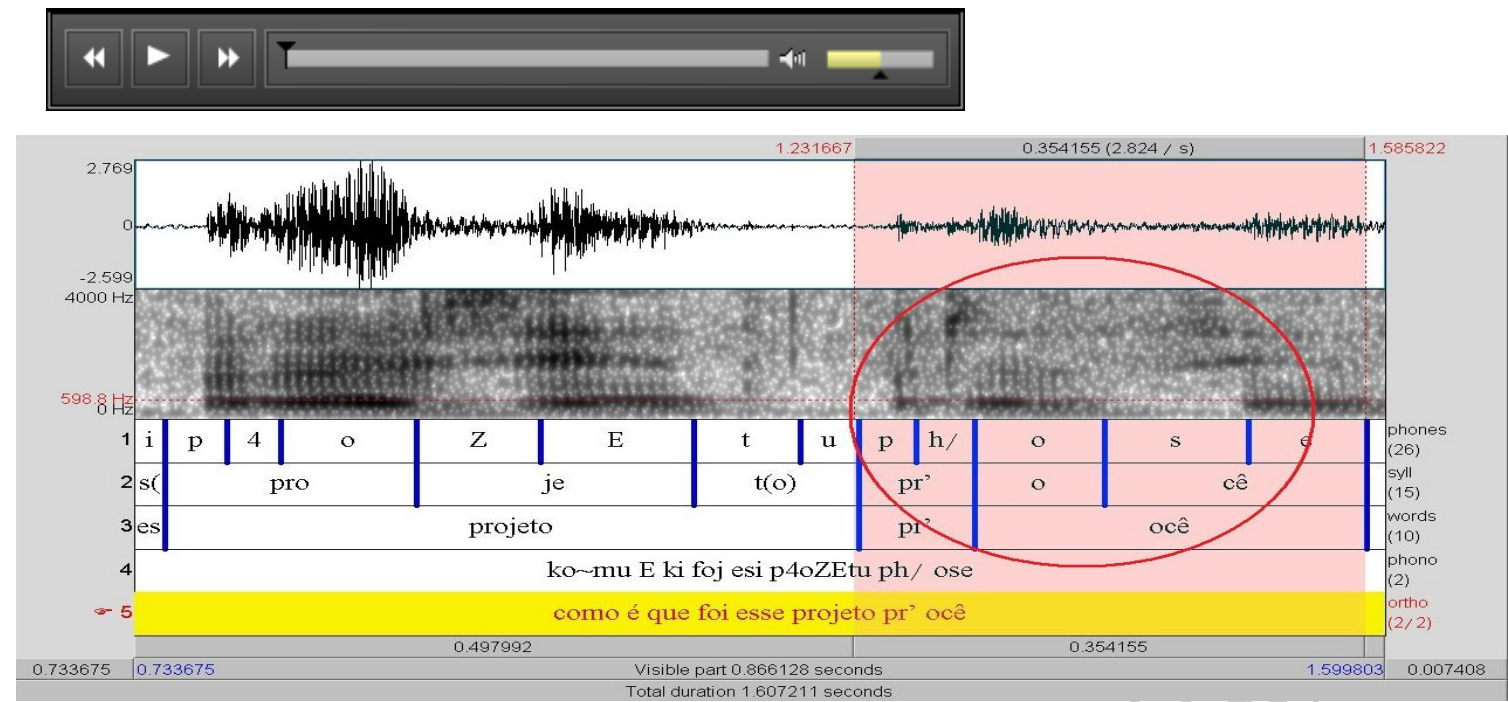

Figura 1: Tela do Praat com o texto (bfamdl11-241), exemplo (20): é mostrado o espectrograma e nas linhas abaixo o texto, e sua segmentação em palavras, sílabas fonética e fones.

O espectrograma do exemplo (20) mostra claramente a presença, após a oclusiva, do tepe e da vogal na série $p r^{\prime}$ ocê.

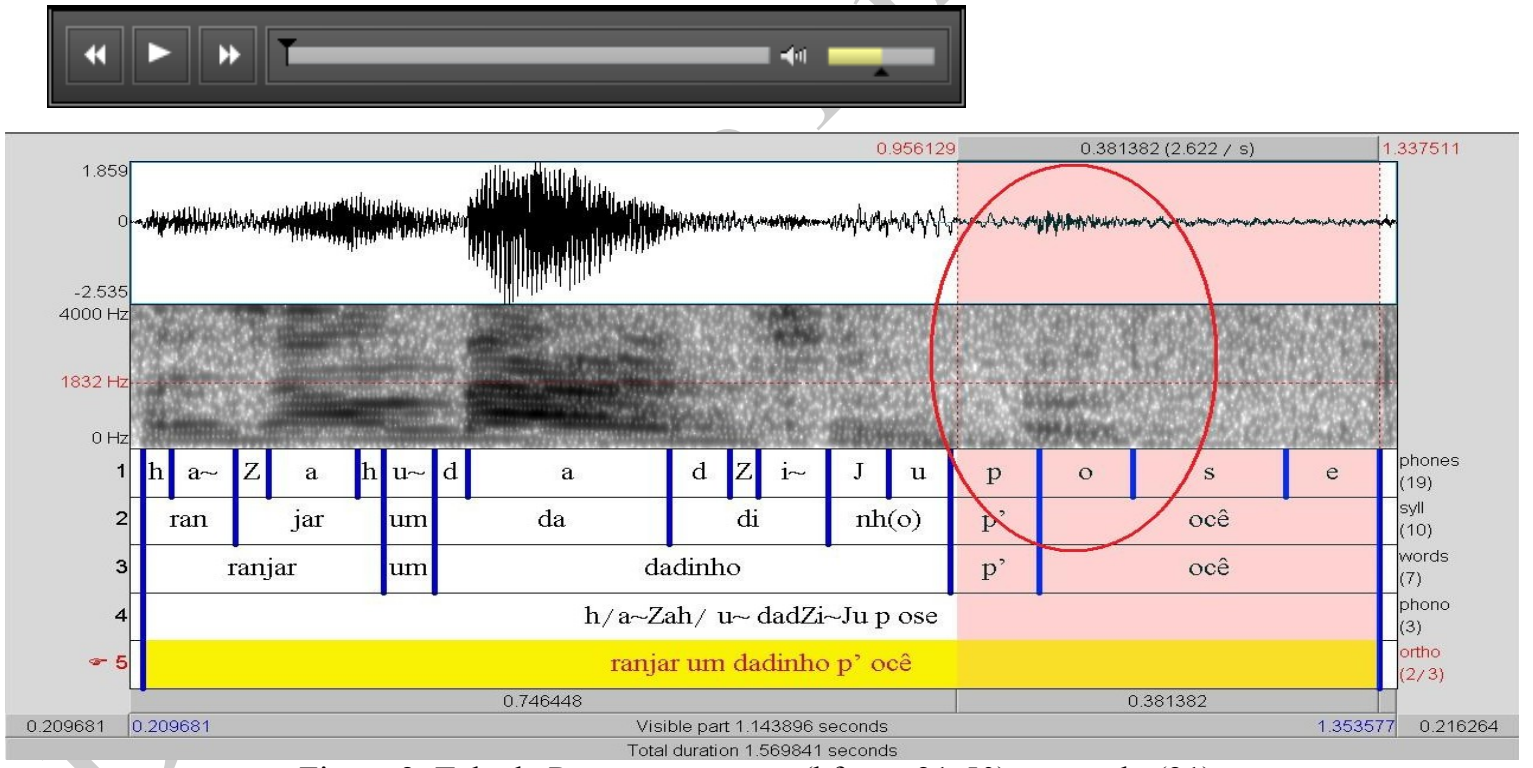

Figura 2: Tela do Praat com o texto (bfamcv21-50), exemplo (21).

Neste espectrograma do exemplo (21), a explosão do $/ p /$ é imediatamente seguida pela vogal, visível pela variação dos pulsos na frequência e pelo ligeiro escurecimento do espectrograma onde há a vogal. 

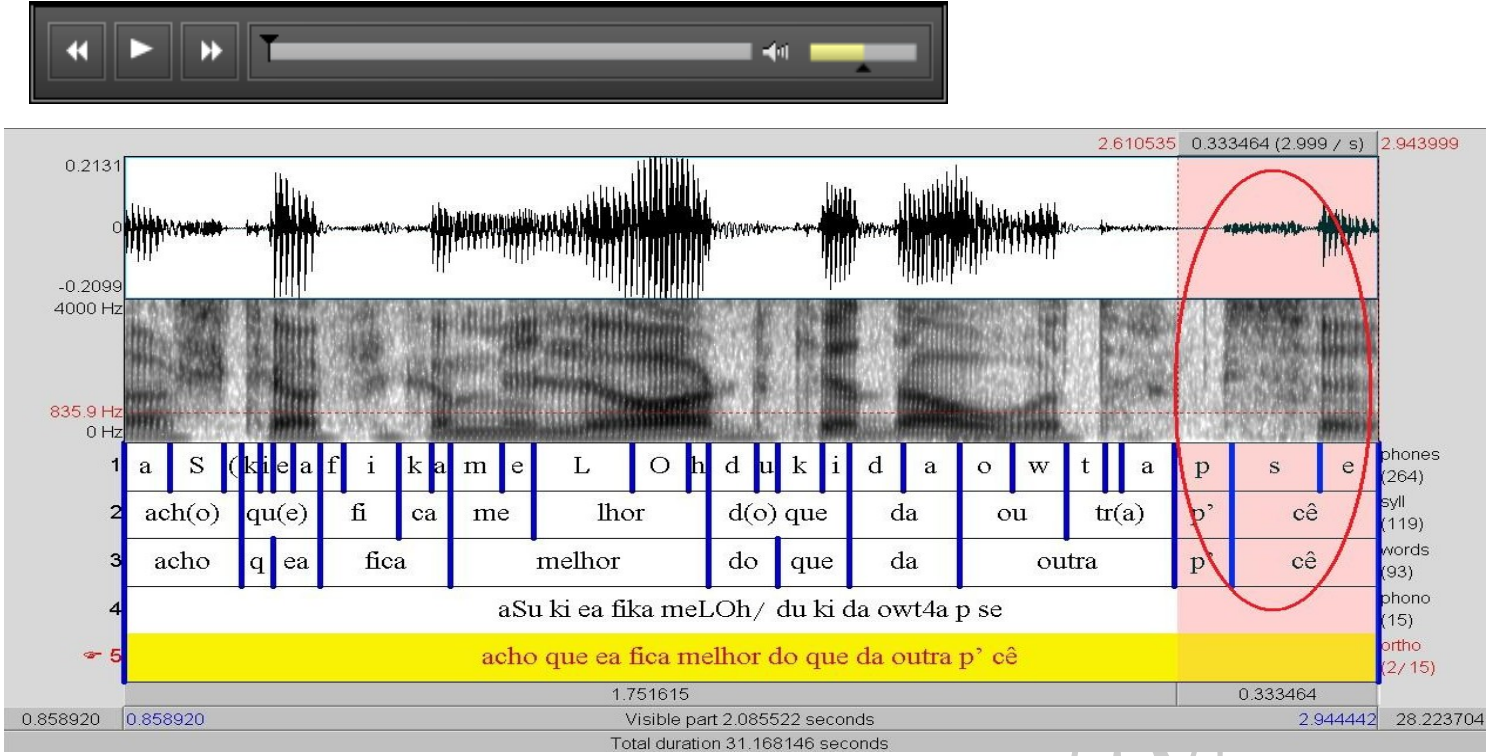

Figura 3: Tela do Praat com o texto (bpud101-90-91), exemplo (22).

Neste caso ao contrário, do exemplo (22), é visível que entre a explosiva e a sibilante não há nenhuma vogal.

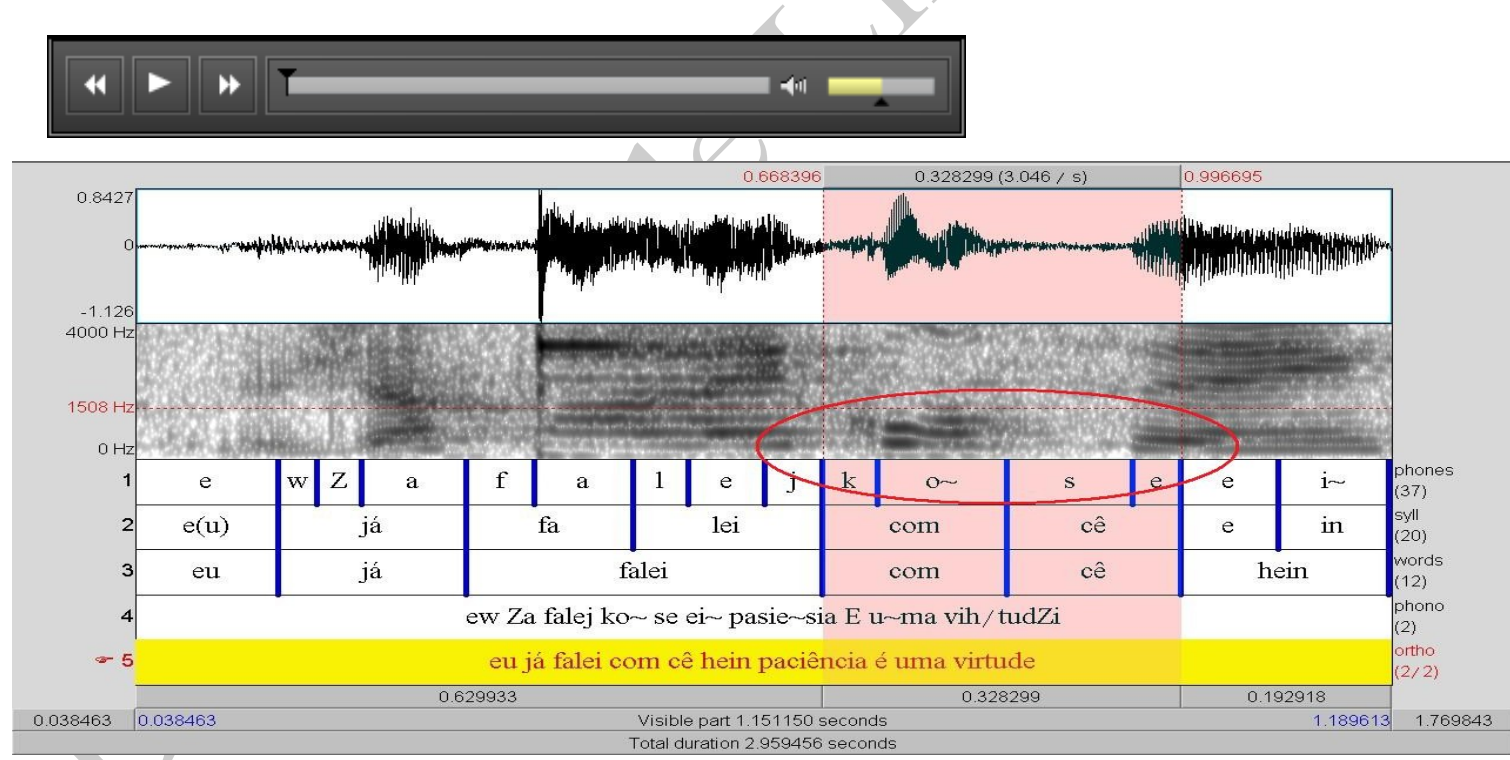

Figura 4: Tela do Praat com o texto (bfamdl12-21), exemplo (24).

No espectrograma do exemplo (24), são perfeitamente visíveis a oclusiva seguida da vogal nasalizadas e da consoante nasal $[\mathrm{m}]$. 

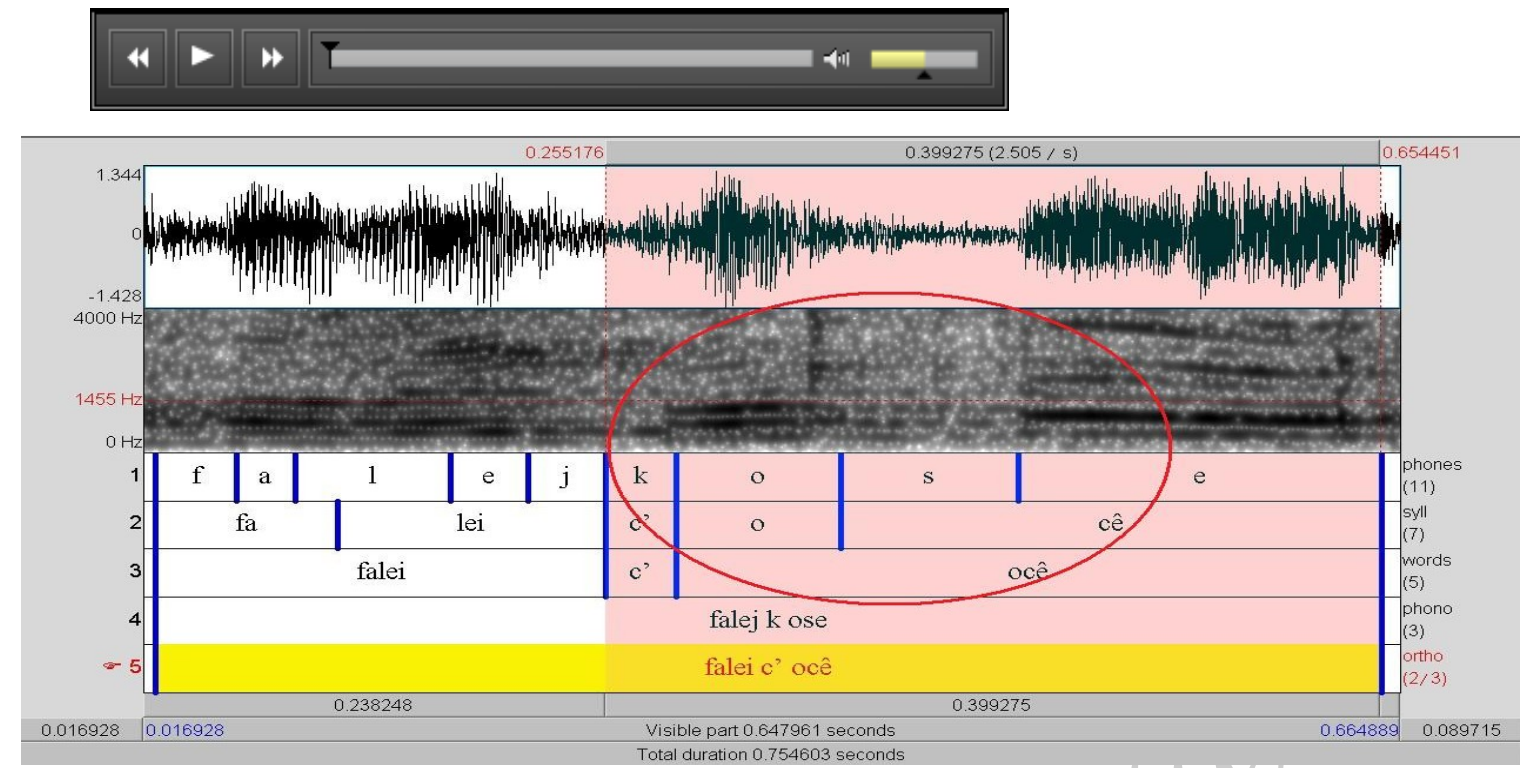

Figura 5: Tela do Praat com o texto (bfamdl30-68), exemplo (19).

Já no exemplo (19), é evidenciada a ausência da consoante nasal.

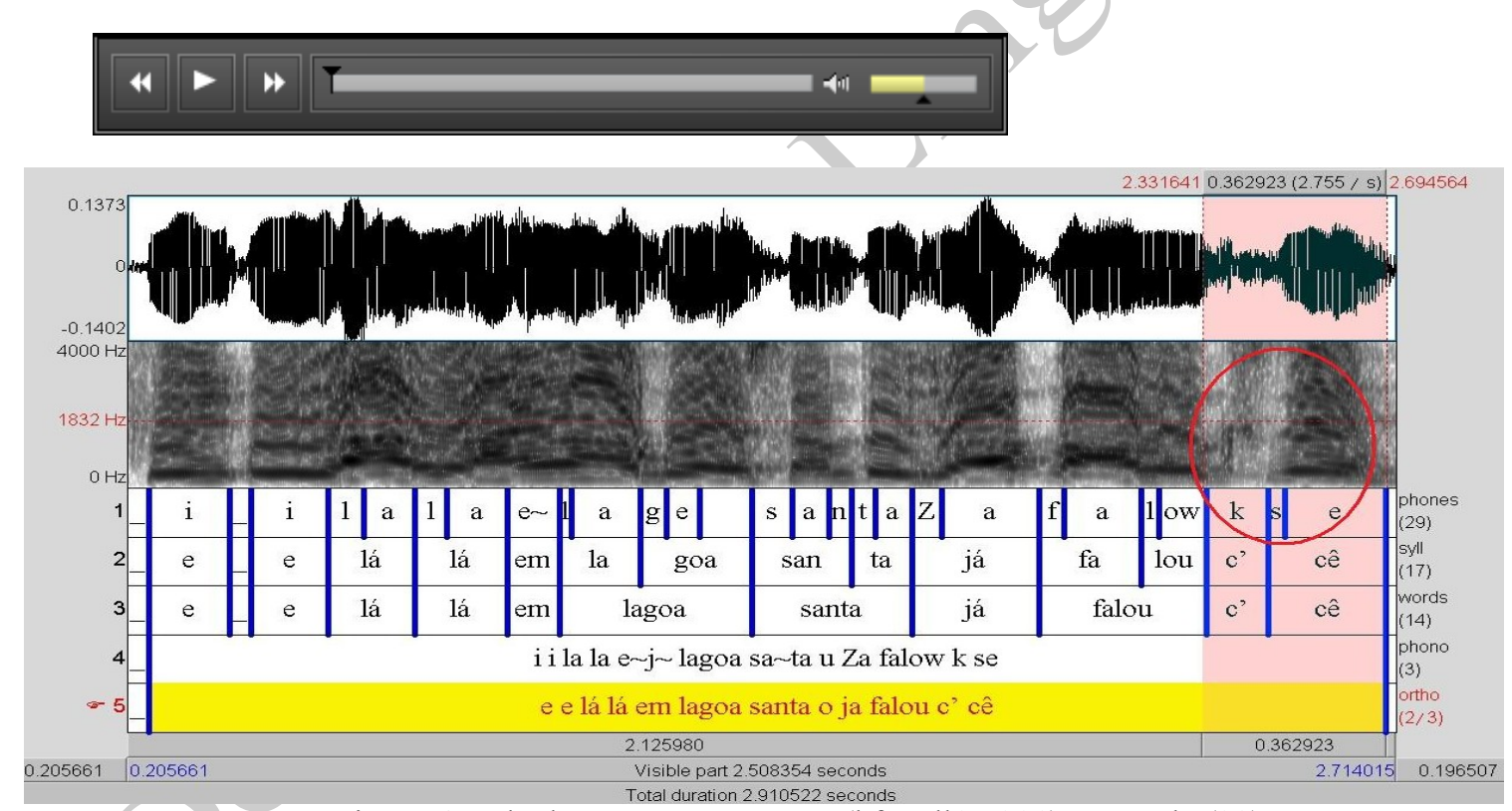

Figura 6: Tela do Praat com o texto (bfamdl17-201), exemplo (23).

No caso do exemplo (23), da oclusiva passa-se diretamente para a fricativa, sem vogal ou consoante nasal. 


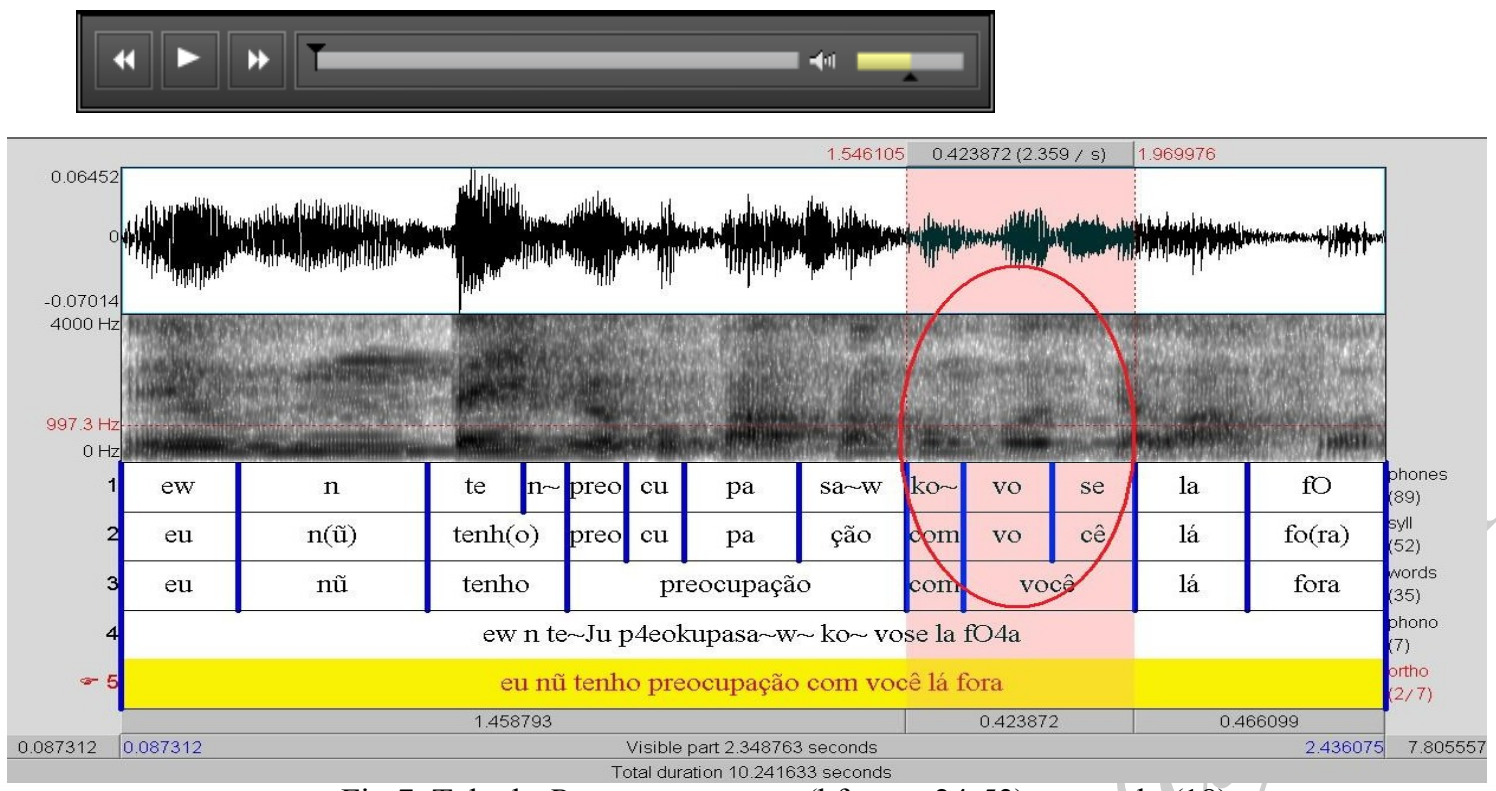

Fig.7: Tela do Praat com o texto (bfammn24-53), exemplo (18).

Finalmente, o exemplo (18), mostra o inteiro processo articulatório que leva da oclusiva às nasais (vogal e consoante), seguida de fricativa e vogal,

Esses exemplos portanto, mostram, com todas as evidências, a possibilidade de a forma cê comparecer como complemento de preposição.

\subsubsection{Pronomes com função contrastiva}

As formas $c \hat{e}(s) / o c \hat{e}(s) / v o c \hat{e}(s)$ foram analisadas também em posições no enunciado que dificilmente seriam encontradas na fala guiada, mas que podem ocorrer na fala totalmente espontânea em contexto natural. É o caso do pronome com função contrastiva. Retomamos, na tabela 6, parte da tabela 2 para relembrar as ocorrências:

Tabela. 6: Ocorrências das formas $c \hat{e}(s) / o c \hat{e}(s) / v o c \hat{e}(s)$ com função contrastiva.

\begin{tabular}{|c|c|c|c|c|c|c|}
\hline POSIÇÃO & $c \hat{e}$ & $c \hat{e} s$ & $o c \hat{e}$ & ocês & você & vocês \\
\hline Pronome com função contrastiva & 0 & 0 & 2 & 0 & 6 & 0 \\
\hline
\end{tabular}

Pode-se notar que a forma $c \hat{e}(s)$ nunca ocorre com essa função, a forma ocê(s) ocorre duas vezes e a forma vocês(s) é a mais frequente com 6 ocorrências.

Vajamos alguns exemplos abaixo.

(26) *ONO: eu cheguei primeiro que ocê// (bfamcv11)

(27) *DUD: não / você / $\operatorname{sim} / /<\& \mathrm{~m}[/ 1] \& \mathrm{~m}>$ [/1] mas ninguém mais // (bfamdl24) 


\subsubsection{Pronome isolado em enunciado ou em unidade tonal}

O corpus C-ORAL-BRASIL representa a segmentação prosódica da fala na transcrição com base em critérios específicos. Tanto os critérios de segmentação quanto a sua validação podem ser conferidos de maneira aprofundada em Raso e Mittmann (2009), Moneglia et. al. (2010) e Mello et al. (2012). A segmentação é a mesma realizada na maioria dos corpora de fala espontânea de terceira geração, como o Santa Barbara Corpus (DU BOIS et al. 2000-2005), o C-ORAL-ROM (CRESTI; MONEGLIA, 2005), o Corpus AfroAsiático (METTOUCHI; CHANARD 2010) e o Corpus CoSIH (HARY, 2003).

Basicamente, o corpus representa a fala segmentada em enunciados, e esses segmentados em unidades tonais (uma ou mais). O enunciado é definido como "a menor unidade da fala interpretável pragmaticamente (e prosodicamente) em isolamento" (CRESTI, 2000; CRESTI; GRAMIGNI, 2004), ou seja, o enunciado é o equivalente da locução de um ato de fala (AUSTIN, 1962). Dentro do enunciado, cada unidade tonal corresponde a uma unidade informacional (CRESTI, 2000; RASO, 2012), cada uma com seus próprios parâmetros funcionais, prosódicos e distribucionais. Portanto, se um pronome se encontra isolado em um enunciado, é necessário que esse pronome seja associado a uma força ilocucionária (deve ser suficiente para realizar um ato de fala). Destarte, se o enunciado é composto por apenas um pronome, o pronome deve ser tônico, como mostrado nos exemplos a seguir, em negrito.

(28)

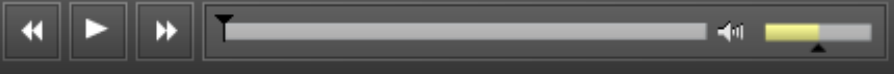

*EDU: porquinho //

*KAR: ahn / <então conta / pra ver> //

*ISA: <não / \&cha [/1] canta da Chapeuzim Vermelho $>$ //

*EDU: <ah / não $>/ /<$ você $>/ /$ você //

*KAR: tá // era uma vez /

*EDU: um porquim //

*ISA: deixa contar agora //(bfamcv17)

(29)

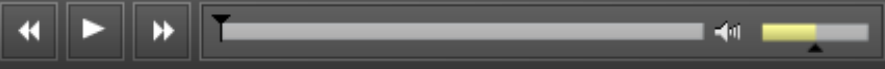

*JAD: <a senhora $>$ // você pediu de qual //

*PTG: ahn //eu vou experimentar frango com \&ched [/2] ih // com cheddar //

*JAD: a senhora não / né // você //(bpubd107) 


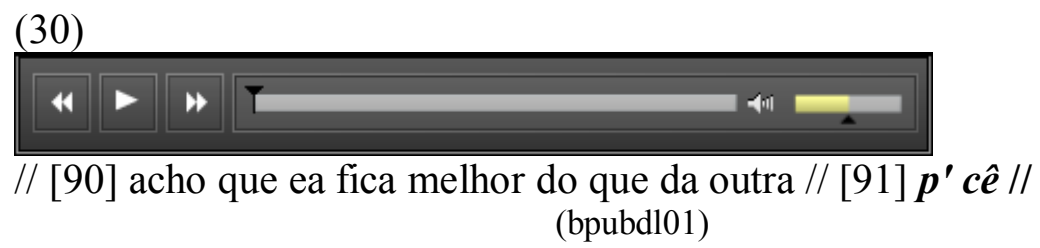

O exemplo 30 mostra, através de outro caminho, o valor tônico das formas de preposição mais $c \hat{e}$. Isso pode ser verificado através das medidas prosódicas.

Quando um pronome se encontra isolado em uma unidade tonal dentro de um enunciado, ele não constitui necessariamente uma unidade informacional. Nesse caso, as possibilidades são várias $^{16}$ :

a) A unidade tonal é apenas parte de uma unidade informacional que é realizada em mais de uma unidade tonal; isso acontece relativamente pouco na fala espontânea, e sempre por certas razões: ou quando o conteúdo locutivo da unidade é grande demais (ou seja, por razões articulatórias), ou quando por razões de diastratia ou idade o falante não possui uma perícia adequada da fala; ou, mais raramente, por razões enfáticas. Essas unidades tonais que realizam apenas uma parte da unidade informacional e nunca a parte final, que é a parte que carrega o perfil funcional da unidade, são chamadas de unidades de escansão (SCA);

b) A unidade tonal pode coincidir com a unidade ilocucionária (que é obrigatória) e o pronome então deve ser tônico;

c) A unidade informacional é uma unidade de tópico, que, por definição, possui um foco funcional, que a torna tônica;

d) A unidade informacional pode ser de outro tipo, e, portanto, pode ser realizada com duração variável.

Observamos todos os 8 casos de cê isolados em unidade tonal. Como era de se esperar, quase todos são unidades de escansão e átonos; observamos que não é necessário que a unidade de escansão seja marcada por uma duração curta. Aqui a seguir se apresentam alguns exemplos, e o espectrograma de dois deles:

\footnotetext{
${ }^{16}$ Não é possível, por razões de espaço, explicar mais em detalhe como se configura a organização da fala espontânea segundo a visão, baseada em observação de corpora de fala espontânea, que adotamos aqui. Para maiores informações, veja-se Cresti (2000), Moneglia (2005) e Raso (2012b).
} 


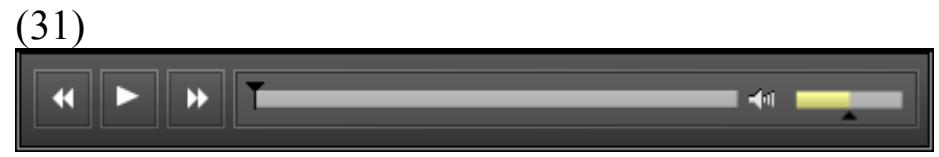

// cê / vai atravessar a praça / (bfamcv14-22)

(32)

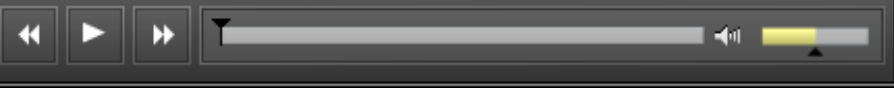

/ cê / faz aquilo que cê / deveria ter feito / (bfamcv32-105)

(33)

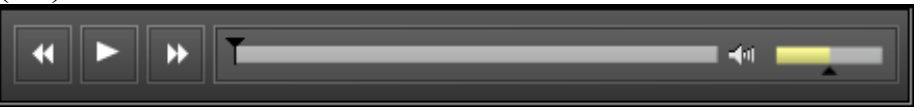

/ cê / sai daqui de casa / (bfammn24-52)

(34)

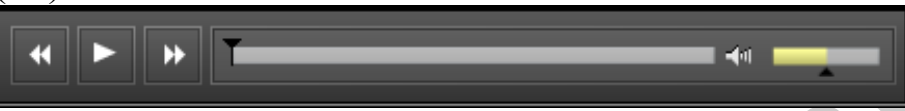

// cê / higieniza / limpa / mata os funguinhos // (bfammn27-64)

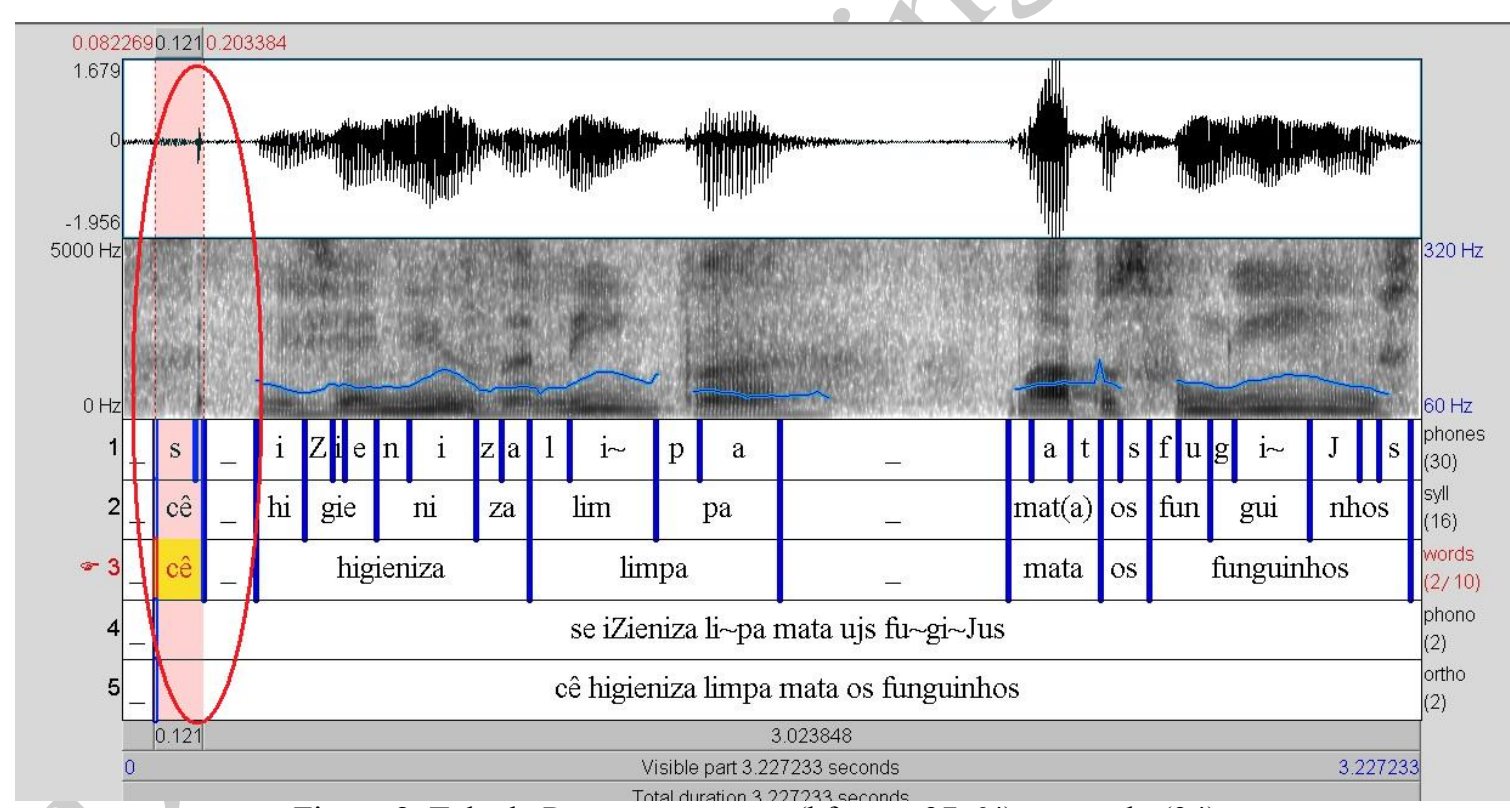

Figura 8: Tela do Praat com o texto (bfammn27-64), exemplo (34).

O espectrograma evidencia um cê extremamente curto como duração e visivelmente átono, seguido de uma páusa, ressaltando o isolamento em unidade tonal.

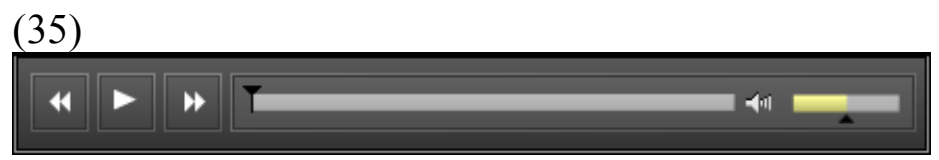

/ tipo / cê / acertar direitinho / (bfamcv31-187) 


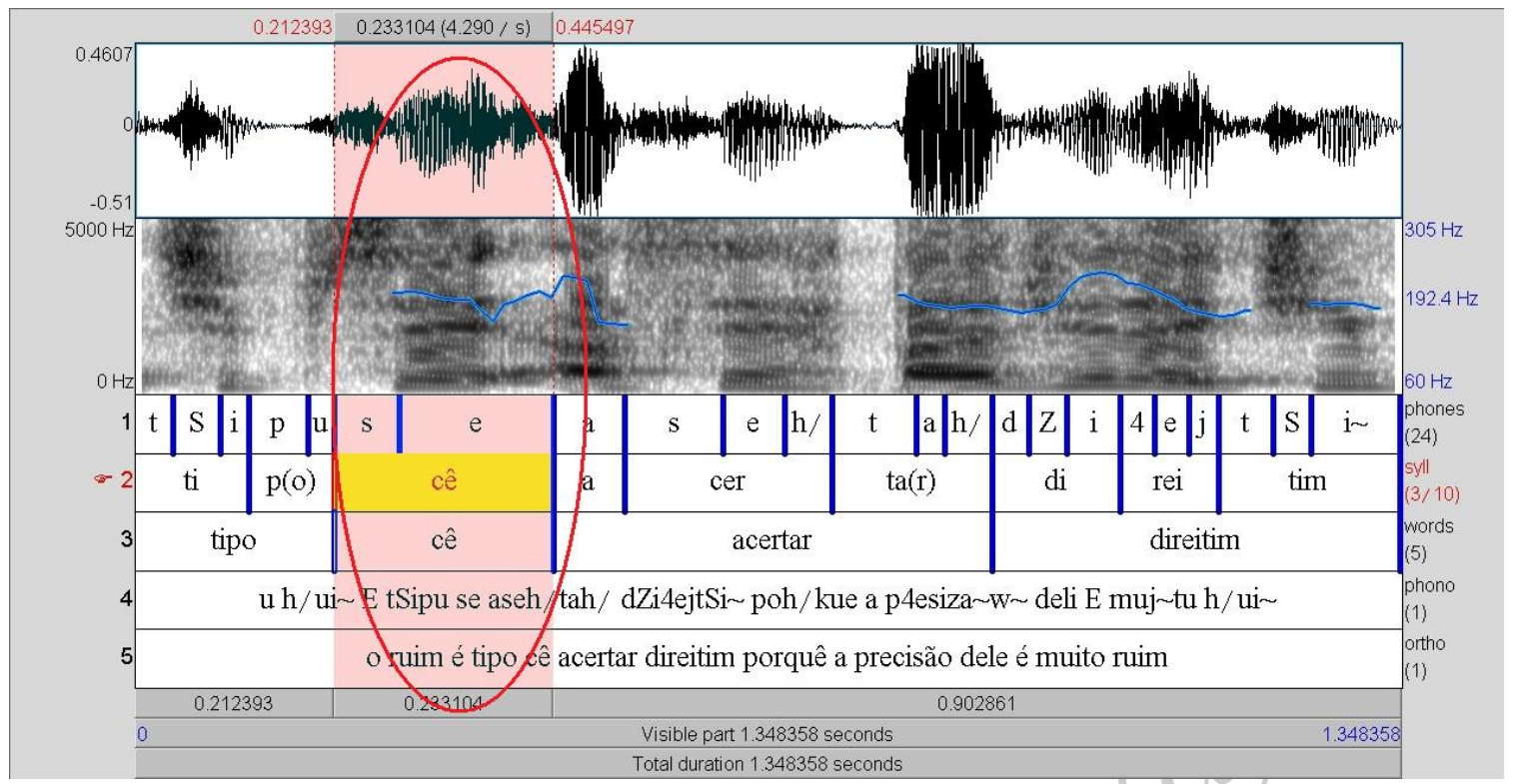

Figura 9: Tela do Praat com o texto (bfamcv31-187), exemplo (35).

Neste caso o pronome é um pouco mais longo do que o anterior, mas sempre átono. Não há pausa, mas uma quebra prosódica após o pronome, que caracteriza seu isolamento em unidade tonal.

Contudo, em um caso, o cê parece fortemente realizar uma unidade de tópico. Trata-se do exemplo seguinte:

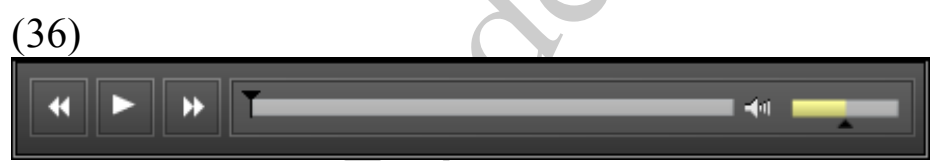

// [47] cê / mandava [/1] \&re [/1] correspondia por carta (bfammn02-47)

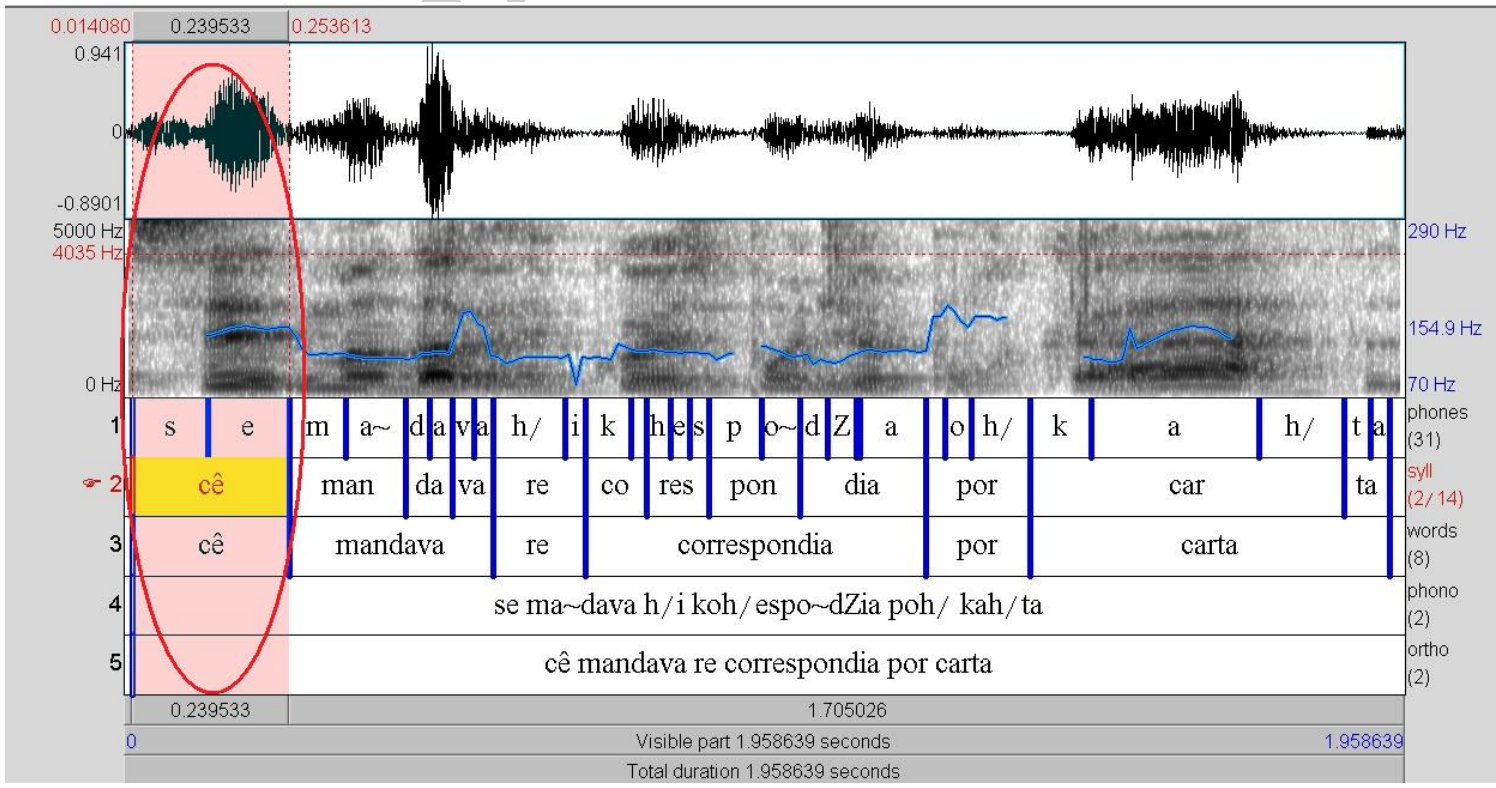

Figura 10: Tela do Praat com o texto (bfammn02-47), exemplo (36). 
A percepção da função de tópico é evidente à oitiva, mas é também corroborada pelos parâmetros prosódicos, basicamente pelo alongamento e pelo perfil ${ }^{17}$. Os estudos realizados sobre as formas de tópico sobre o italiano (FIRENZUOLI; SIGNORINI, 2003), o PB (MITTMANN 2012) e o PE (ROCHA 2012) mostraram que são possíveis quatro formas. O exemplo mostrado na fig. 10 corresponderia à segunda forma, caracterizada por um núcleo (que nesse caso envolve a única sílaba da unidade) ascendente com alongamento.

É evidente que um único caso não é suficiente para provar que a forma cê possa realizar a função de tópico. Seria necessário dispor de um corpus maior para poder achar outros exemplos. Contudo, nos parece muito interessante mostrar um caso em que a forma cê chega a ser um bom candidato para a função de tópico, e certamente apresenta características prosódicas de tonicidade.

\section{Análise acústica}

Os estudos prosódicos identificam três parâmetros que devem ser observados no momento da análise da produção: a duração, entendida como a diferença de tempo entre dois eventos; a frequência fundamental $(F 0)$, determinada pelo número de ciclos que as pregas vocais fazem em um segundo; e a intensidade, devida à energia de vibração da fonte que emite o som. A percepção da fala relaciona esses três parâmetros às noções de duração percebida, altura e volume. Segundo Barbosa (1999), a sensação de duração percebida está diretamente ligada ao cruzamento dos três parâmetros prosódicos citados acima como um todo. No estudo da fala, a análise prosódica se dá, geralmente, "pelo estudo da duração observada, deixando-se de lado os papéis desempenhados pela frequência fundamental e pela intensidade em sua percepção" (BARBOSA, 1999, p. 23).

A parte mais árdua, e também mais inovadora deste trabalho, consiste na análise acústica dos enunciados em que se encontram as formas $c \hat{e}(s) / o c \hat{e}(s) /$ você( $(s)$. O objetivo é verificar a duração dessas formas comparando-as com a duração das outras sílabas do mesmo enunciado. Medir a duração silábica na fala espontânea é uma tarefa muito complexa: o conteúdo locutivo de cada enunciado é extremamente variável; podem ocorrer mudanças extremas de velocidade de fala, até mesmo na fala de um mesmo falante; várias formas de ruído podem introduzir

\footnotetext{
${ }^{17}$ Sobre o tópico em PB veja-se Raso, 2012b e principalmente Mittmann, 2012 e Mittmann e Rocha, 2012.
} 
fatores de ulterior complicação. Para minimizar a variabilidade nos dados, que são de enunciados não padronizados, foi realizada a comparação das sílabas de um mesmo enunciado. Esse procedimento permite saber se a(s) sílaba(s) do pronome estudado encontra(m)-se entre aquelas mais longas do mesmo enunciado ou entre aquelas mais curtas. Como discutido abaixo, os critérios de segmentação fonética são tarefas complexas. Trata-se das decisões que devem ser tomadas para escolher as fronteiras entre um evento e outro, e de definir por qual, dentre a variedade de fenômenos observáveis no sinal de fala, deve-se optar.

Para se chegar aos resultados da segmentação, foram seguidas as seguintes etapas:

1) Seleção dos enunciados adequados, cujos critérios serão descritos abaixo. Foi feita manualmente uma busca nas planilhas do tipo Excel, criadas na primeira etapa do trabalho, dos enunciados em que ocorressem as formas cê(s)/ocê(s)/você(s);

2) Busca, através do programa WinPitch, dos enunciados selecionados na etapa 1. Através do WinPich, é possível visualizar o alinhamento do texto com o som e a conferência da qualidade do espectro acústico e da boa audibilidade do som. Em caso afirmativo, o trecho em questão foi selecionado, copiado e transferido para uma pasta separada;

3) Abertura do arquivo de áudio no programa Praat (BOERSMA; WEENINK, 2013) e segmentação do enunciado em palavras, sílabas e fones;

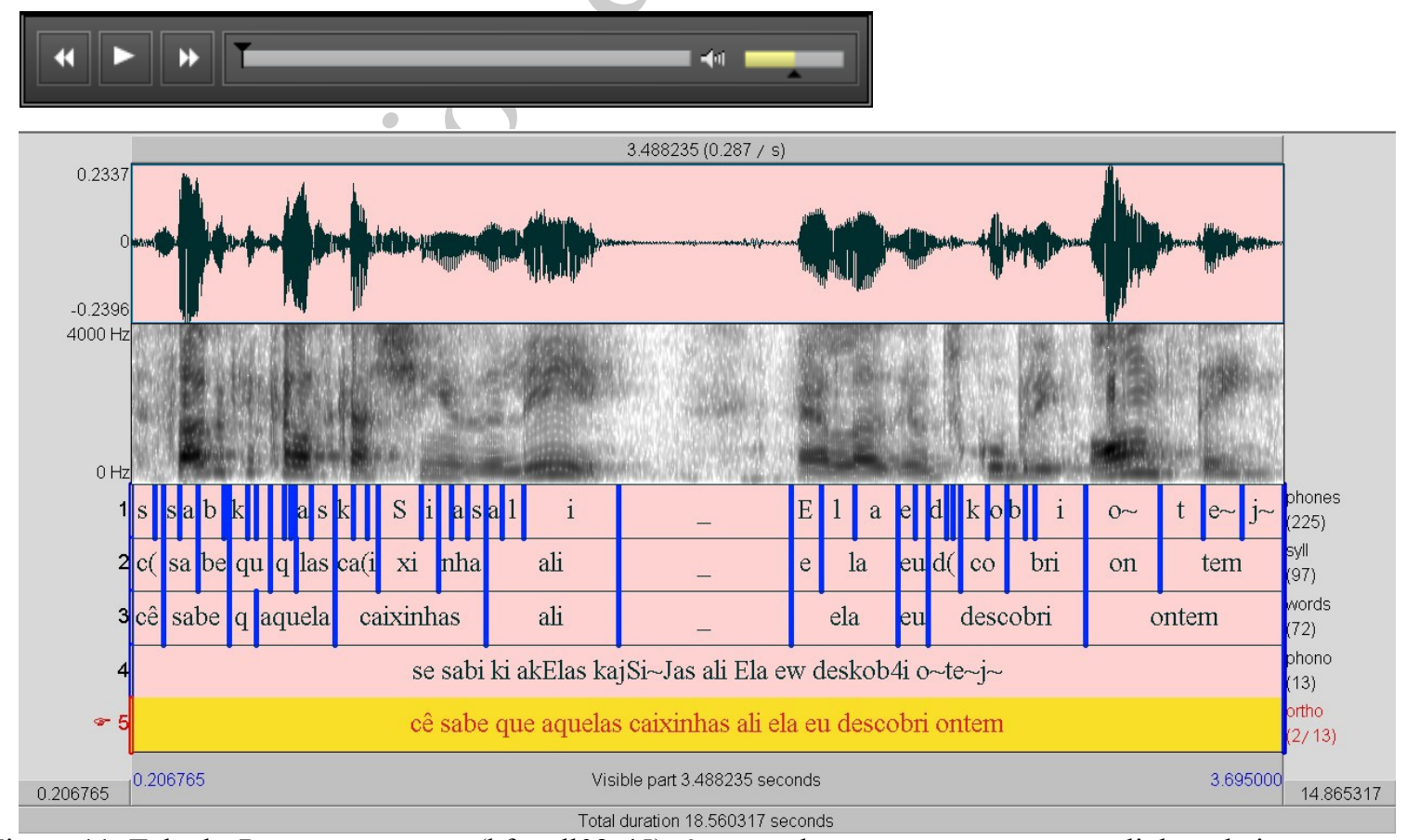

Figura 11: Tela do Praat com o texto (bfamd102-45): é mostrado o espectrograma e nas linhas abaixo o texto, e sua segmentação em palavras, sílabas fonética e fones. 
4) Extração dos dados relativos à duração das sílabas de cada enunciado e conversão em formato compatível com uma planilha do tipo Excel para análise estatística.

\subsection{Seleção dos enunciados}

Seguindo os passos metodológicos descritos, foram selecionados 110 enunciados extraídos do corpus e com as seguintes características:

a) conter pelo menos uma ocorrência das formas $c \hat{e}(s) / o c \hat{e}(s) /$ você( $(s)$;

b) possuir uma alta qualidade acústica (segundo os critérios do C-ORAL-BRASIL qualidade $\mathrm{A}$ ou $\left.\mathrm{AB}^{18}\right)$;

c) não fazer parte de enunciados com sobreposição de fala.

Tais critérios garantiram uma amostra de enunciados que contivessem suficiente qualidade acústica para a análise do espectro da fala.

Os 110 enunciados obtidos pertencem a 29 informantes diferentes, 16 de sexo masculino e 10 de sexo feminino. Desses informantes, 11 possuem até o terceiro grau completo, mas não atuam em profissão que exige o título (classe 2) e 14 possuem terceiro grau completo e exercem uma atividade que necessita deste tipo de escolarização (classe 3). Três falantes possuem o primário incompleto (classe 1) e sobre o último não se possuem informações de seu nível escolar $^{19}$. Quanto à origem dos falantes: 11 são de Belo Horizonte, 3 da região metropolitana, 11 do interior de Minas Gerais e um de origem desconhecida.

Foram então realizadas as etapas de extração dos arquivos, como descrito acima, e análise e segmentação no programa Praat.

\subsection{Critérios de segmentação}

O estudo da duração requer do pesquisador a decisão sobre qual evento do sinal acústico deve ser utilizado como fronteira para delimitação entre o início e o fim do tempo mensurado. Segundo Barbosa (1999), sempre existirá uma certa dose de incerteza, devido aos fenômenos de coarticulação. O termo segmentação é definido por Barbosa como "a marcação dos eventos que foram escolhidos para a caracterização da duração”.

\footnotetext{
${ }^{18}$ Para os critérios de avaliação da qualidade acústica das gravações remetemos ao parágrafo 3.1 "A qualidade acústica” do cap. 2 "O corpus C-ORAL-BRASIL" (RASO, 2012a).

${ }^{19}$ Sobre a variação diastrática do corpus C-ORAL-BRASIL e as escolhas dos diferentes níveis de escolaridade, veja-se o capítulo 2 "O corpus C-ORAL-BRASIL” de RASO (2012).
} 
Nesse caso, os indicadores principais de segmentação foram a análise do espectrograma e a percepção do sinal acústico.

O enunciado inteiro é ouvido e, com base em uma primeira impressão, são marcadas em uma linha (TextGrid) as fronteiras entre palavras. Devido a vários fenômenos (ruído de fundo e coarticulação são os mais relevantes), nem sempre é possível detectar todas as fronteiras; portanto são importantes a observação e a interpretação do espectrograma, que fornece um "retrato" das ondas acústicas produzidas na fala. Exemplificando esse discurso, a observação dos formantes, ou seja, das frequências de ressonância em volta dos quais se formam picos de amplitude, é um bom indício para a localização das vogais. Já as oclusivas são precedidas por um período de silêncio após o qual há uma "explosão" assinalada no espectrograma com uma linha vertical bastante reconhecível. Sem esquecermos a importância do reconhecimento da sibilante no $c \hat{e}(s)$.

Há, portanto, vários indícios que permitem assinalar as fronteiras entre fones. Como o interesse da pesquisa está nas sílabas, foi importante poder detectar primeiramente os fones, para depois efetuar sua junção em sílabas.

O próprio programa Praat fornece o auxílio do pacote Easyalign, que faz uma segmentação grosso modo dos enunciados em palavras, sílabas e fones. Contudo o script não é totalmente confiável e, em se tratando de fala espontânea, precisou ser corrigido manualmente.

A parte do estudo que aqui é apresentada trabalhou com sílabas ortográficas, porque o corpus é transcrito ortograficamente, com poucas modificações. Na etapa que está em andamento, essas sílabas serão todas reescritas em transcrição fonética ampla ${ }^{20}$, em formato $A S C I I$, para que possam ser analisadas pelo programa SGdetector, como explicado adiante. Deixando de lado a questão do formato da transcrição, as fronteiras permanecem as mesmas, e as análises foram feitas em cima dessas segmentações.

O programa Praat extrai automaticamente a duração de cada sílaba e, como foi dito, os dados são inseridos em uma planilha do tipo Excel para comparação dos dados.

\section{Resultados parciais}

Conforme explicado anteriormente, as sílabas de cada enunciado foram comparadas entre si:

\footnotetext{
20 "broad phonetic transcription", Barbosa, 2013, p. 86
} 
- foi calculada a média das sílabas do enunciado;

- decidiu-se então quais sílabas se aproximavam de valores longos e quais de valores curtos em relação à média do enunciado.

Pode-se visualizar melhor essa etapa com alguns enunciados, desde sua segmentação no Praat, abaixo, à extração dos valores de cada sílaba em milisegundos, ao cálculo da média das sílabas, à decisão final.

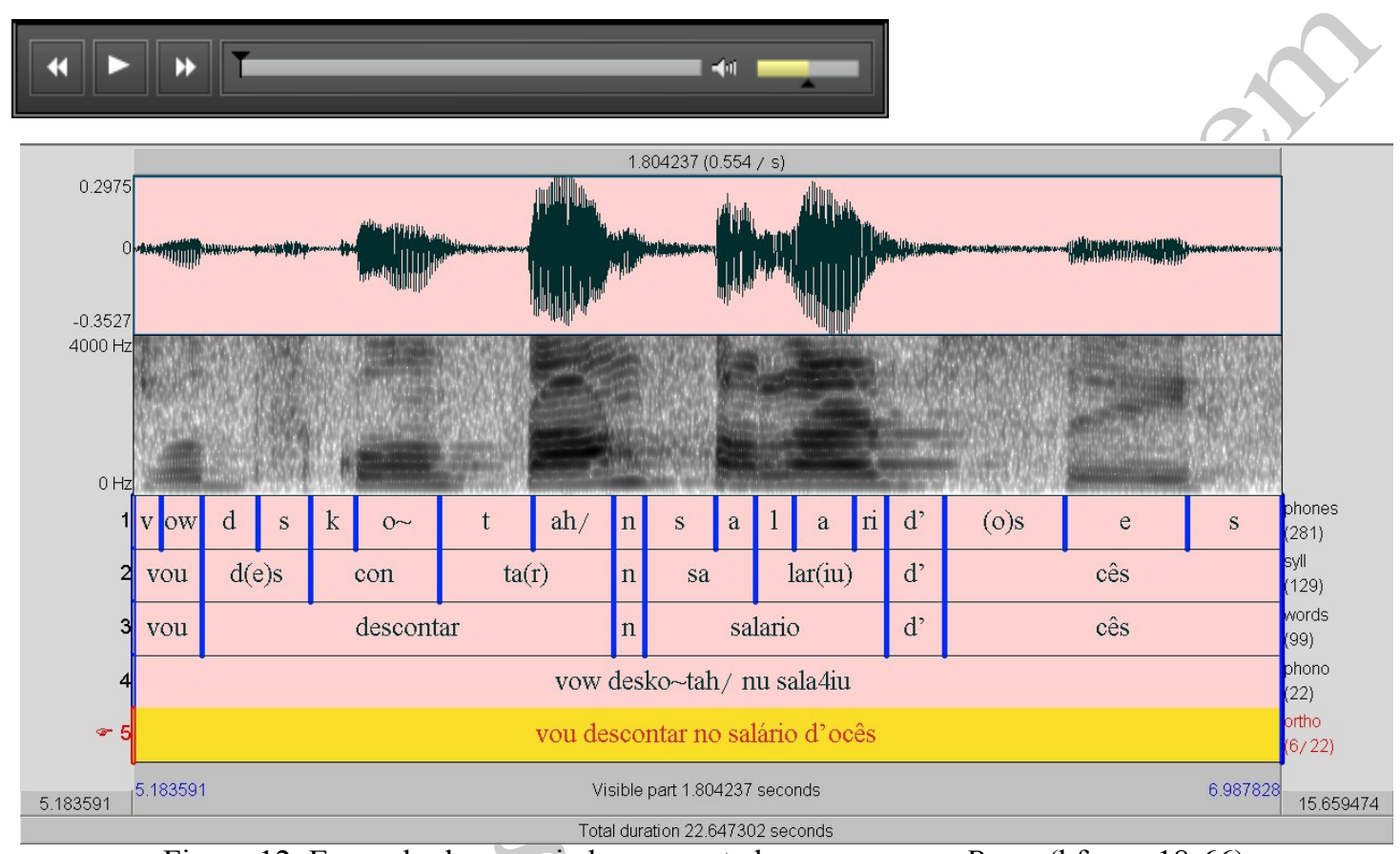

Figura 12: Exemplo de enunciado segmentado no programa Praat (bfamcv18-66)

Na tabela (7) abaixo são mostrados os valores de cada sílaba. As partes entre parênteses são aquelas não pronunciadas efetivamente pelos falantes.

Tabela 7: Duração em milissegundos das sílabas do enunciado (bfamcv18-66).

\begin{tabular}{c|c}
\hline SíLABA & DURAÇÃO EM ms. \\
\hline vou & 108 \\
\hline d(e)s & 170 \\
\hline con & 202 \\
\hline ta(r) & 272 \\
\hline no & 49 \\
\hline sa & 172 \\
\hline lá r(iu) & 206 \\
\hline d' & 90 \\
\hline cês & $\mathbf{5 3 0}$ \\
\hline
\end{tabular}

A duração total do enunciado do exemplo é de 1799 ms. A média de cada sílaba é de 199,9 ms. Pode-se observar que é possível dividir o enunciado entre as sílabas mais curtas e aquelas 
mais longas, tônicas, e que a forma cês pertence às mais longas. Esse pronome, portanto, não pode ser clítico. Observando-se sua posição no enunciado e sua função, trata-se, sem dúvida, de um caso de objeto preposicionado.

Segue outro exemplo, começando com a segmentação e o áudio exibidos no programa Praat.

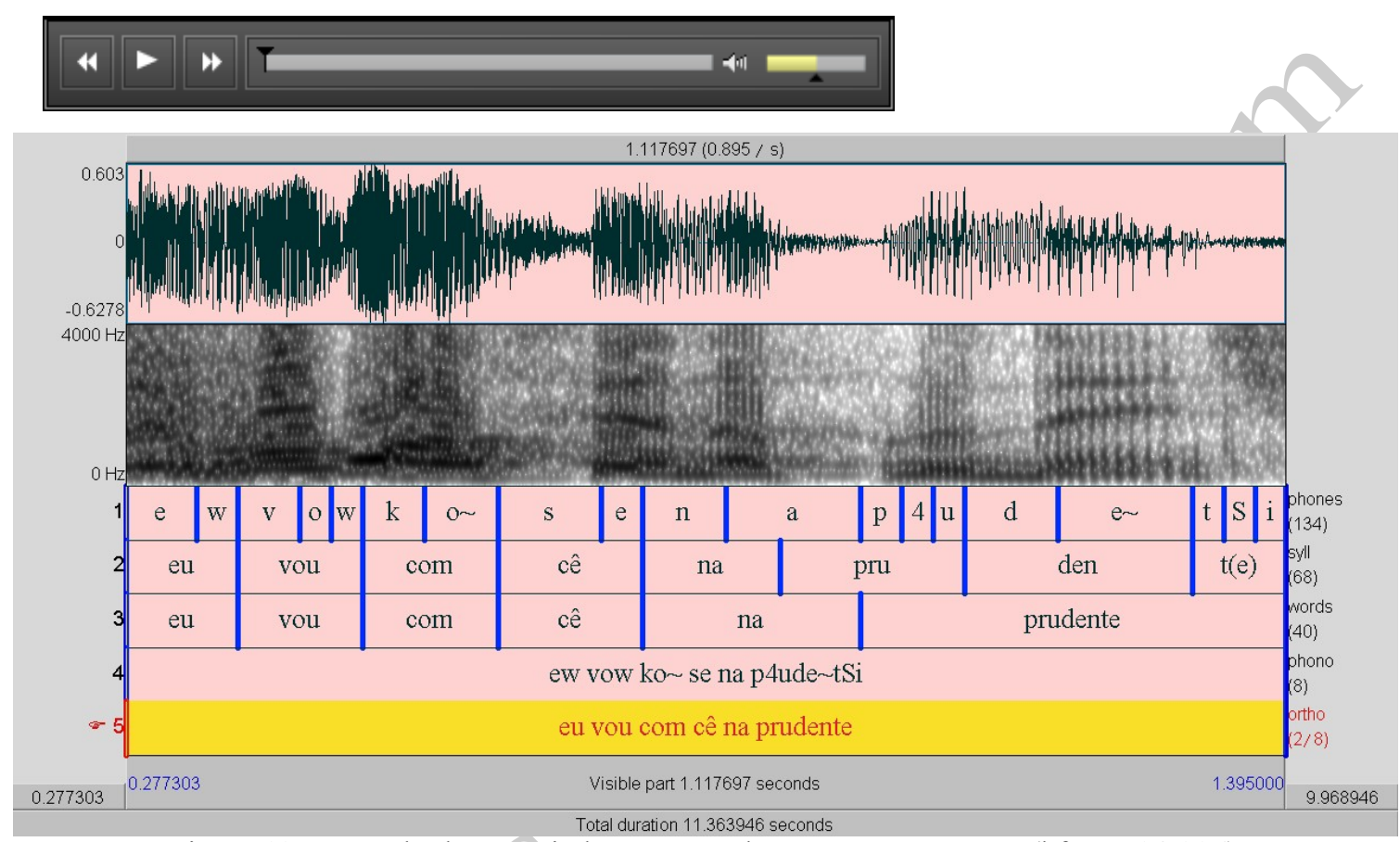

Figura 13: Exemplo de enunciado segmentado no programa Praat (bfamcv14-226)

Nesse caso, a forma analisada é cê. Pode-se ver que o pronome se encontra em posição pós-verbal e com função de objeto preposicionado. A tabela da duração silábica abaixo mostra que, mais uma vez, a sílaba em questão encontra-se entre as mais longas: a duração do enunciado é de 1200ms. A duração média das sílabas é de 150 ms.

Tabela 8:Duração em milissegundos das sílabas do enunciado (bfamcv14-226).

\begin{tabular}{c|c}
\hline SÍLABA & DURAÇ̃̃O EM ms. \\
\hline eu & 6 \\
\hline vou & 121 \\
\hline com & 138 \\
\hline cê & $\mathbf{1 9 2}$ \\
\hline na & 173 \\
\hline pru & 111 \\
\hline den & 223 \\
\hline t(e) & 236 \\
\hline
\end{tabular}


É possível notar que a sua duração, de 192 ms., faz dessa sílaba a mais longa excluindo-se a final, na qual a vogal nem é pronunciada.

Finalmente, mostramos um exemplo em que a forma cê ocupa posição pré-verbal e função de sujeito.

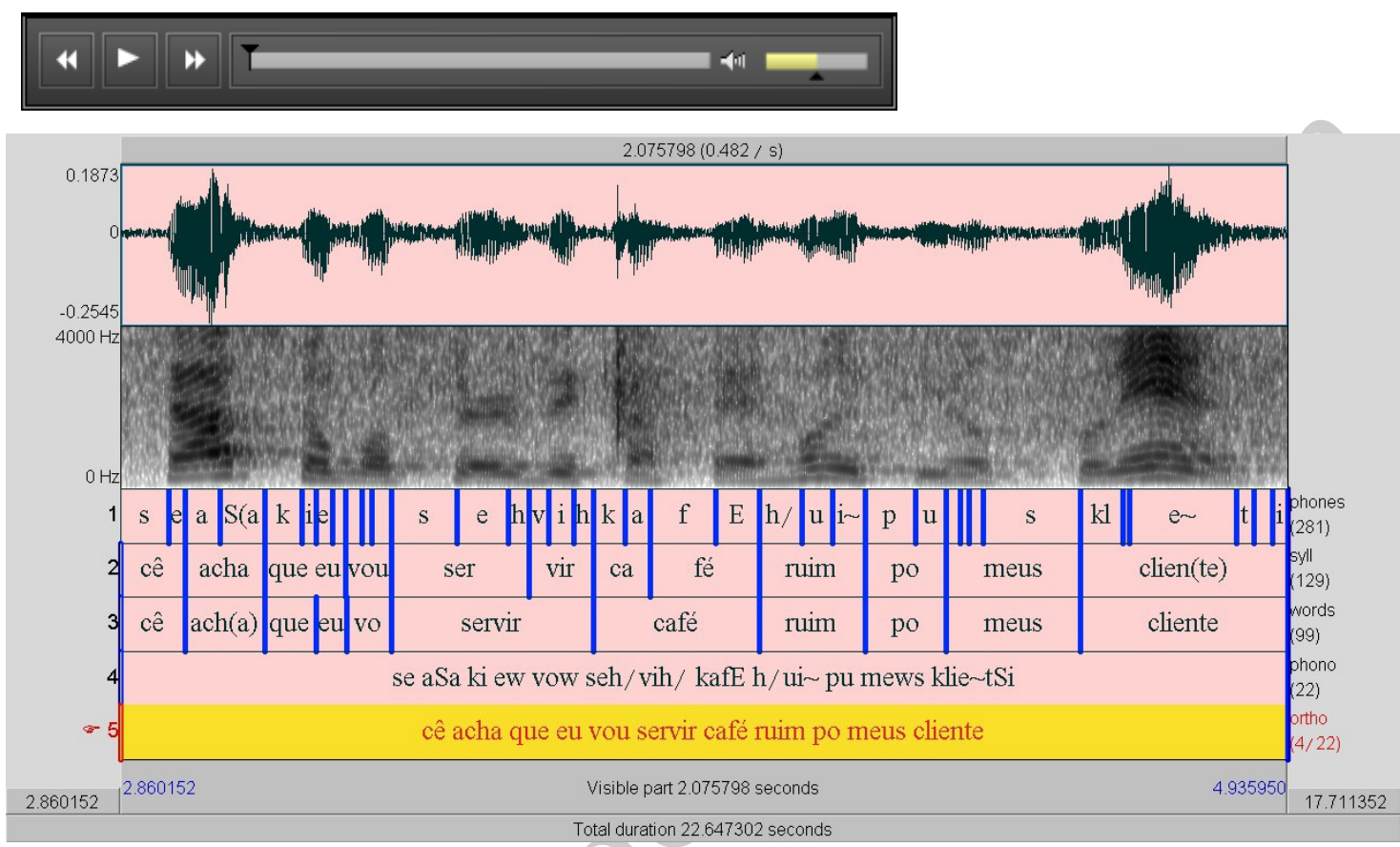

Figura 14: Exemplo de enunciado segmentado no programa Praat (bfamcv18-56).

A duração total do enunciado é de 2085 ms. A média das sílabas é de 173 ms.

Tabela 9: Duração em milissegundos das sílabas do enunciado (bfamcv18-56).

\begin{tabular}{|c|c|}
\hline SÍLABA & DURAÇÃO EM ms. \\
\hline cê & $\mathbf{1 1 5}$ \\
\hline ach(a) & 140 \\
\hline que eu & 145 \\
\hline vou & 79 \\
\hline ser & 244 \\
\hline vir & 115 \\
\hline ca & 101 \\
\hline fé & 193 \\
\hline ruim & 199 \\
\hline po & 145 \\
\hline meus & 239 \\
\hline clien(te) & 370 \\
\hline
\end{tabular}

A sílaba cê apresentou uma duração de $115 \mathrm{~ms}$, colocando-a entre as sílabas curtas do enunciado. 
O que foi observado na análise dos 110 enunciados, dos quais três foram aqui mostrados em detalhes, é que parece haver uma tendência muito evidente que aponta para os seguintes fatos:

I) As sílabas da forma $c \hat{e}(S)$ em posição pré-verbal e função de sujeito se encaixam entre as sílabas curtas dos enunciados a que pertencem.

II) As sílabas da forma $c \hat{e}(s)$ em posição pós-verbal e função de objeto preposicionado se encaixam entre as sílabas longas dos enunciado.

III) Esse fato parece ser um forte indício de uma correlação direta entre duração e posição/função. Em outras palavras, a mesma forma segmental cê( $(S)$ pode ter duração longa ou curta e isso assinala a sua função. Quando é longa, deve ser considerada tônica, quando é curta, átona.

IV) As sílabas das formas ocê(s) e você( $(s)$ parecem seguir um padrão similar àquele descrito acima, mas os dados não são tão claros quanto os da forma $c \hat{e}(s)$ e necessitam de maior análise e de uma maior reflexão sobre as implicações dos resultados.

Uma possível objeção ao fato que a forma cê, em função tônica, apresenta uma duração longa devido a um possível alongamento final, deve ser desconsiderada, pois nos exemplos mostrados, e em outros analisados, o cê comparece em várias posições, finais e não finais. Naturalmente, a posição final aumenta ulteriormente o alongamento. Para avaliar de forma completa os exemplos em posição final de enunciado, aguardamos os resultados da normalização dos dados que está sendo implementada. De qualquer forma o que até agora analisamos parece-nos já indicar a necessidade de uma direção de pesquisa que não pode ser desconsiderada.

\section{Desdobramentos futuros}

A análise acústica realizada até este momento deixou algumas questões em aberto. Na mensuração da duração das sílabas, não foram levados em conta os valores intrínsecos que vogais e consoantes possuem. Sílabas com a mesma duração, na realidade, podem possuir valores intrínsecos diferentes, dependendo das vogais, e mesmo de algumas consoantes, que são nelas contidas. 
Será necessário, portanto, implementar uma forma de normalização dos dados, que permita comparar as sílabas diferentes de forma mais sólida. Essa primeira etapa já está sendo testada com o script SGdetector ${ }^{21}$.

A segunda etapa a ser realizada, após esta revisão dos dados, será a aplicação de testes estatísticos que possam medir o grau de confiabilidade dos resultados.

\section{Conclusões}

$\mathrm{O}$ artigo ilustrou uma metodologia inovativa no estudo da redução do pronome você(s) através da linguística de corpus e partindo da análise dos fatores prosódicos que determinam diretamente a tonicidade ou a atonicidade. Os dados fornecidos pelo corpus são dados de fala espontânea em contexto natural. A análise se concentrou sobre as seis formas $c \hat{e}(s) / o c \hat{e}(s) / \operatorname{voc} \hat{e}(s)$.

Os resultados evidenciaram:

1) a massiva utilização da forma $c \hat{e}(s)$ por parte dos falantes da diatopia mineira, representados no corpus utilizado, o C-ORAL-BRASIL;

2) a preferência por parte dos informantes pelo uso da forma $c \hat{e}(s)$ em posição pré-verbal e função de sujeito em relação às formas dissilábicas;

3) a existência, contrariamente ao afirmado pela literatura, de casos da forma $c \hat{e}(s)$ em posição pós-verbal e função de objeto preposicionado. A forma é bastante utilizada nessa posição/função e parece estar relacionada às preposições para, com e de, sendo as preposições também frequentemente reduzidas;

4) a forte probabilidade de que haja uma correlação entre duração e tonicidade/atonicidade e, por conseqüência, entre a duração e a posição/função, não necessariamente entre essas últimas e a forma segmental. A forma $c \hat{e}(s)$, na análise acústica, quando apresentou durações compatíveis com as sílabas curtas do enunciado em que ocorreu, foi encontrada sempre em posição pré-verbal e função de sujeito. Quando suas durações eram compatíveis com as sílabas longas, foi encontrada sempre em posição pós-verbal e função de objeto indireto;

${ }^{21}$ O SGdetector é um script realizado para ser rodado no programa Praat. Ele se baseia na concepção de que a duração é um parâmetro fundamental para assinalar acento, proeminência e fronteiras prosódicas em várias línguas entre as quais o PB. O programa foi implementado em 2004 e aperfeiçoado em 2009 e 2010. Ele permite detectar de maneira semiautomática picos de duração de sílabas e marca as palavras proeminentes pela duração. 
5) wm um único caso foi identificada a forma cê com função de tópico. Trata-se de um dado insuficiente para afirmar que cê pode comparecer com essa função, mas de extremo interesse. Espera-se que essa possibilidade possa ser verificada no futuro quando forem disponíveis corpora com as mesmas características do C-ORAL-BRASIL mas com maiores dimensões.

Este estudo não pretende ser conclusivo. Será necessário normalizar os dados acústicos e submetê-los a testes para a validação estatística. Contudo a pesquisa demonstra que a questão da tonicidade das formas pronominais do PB e a sua distribuição morfossintática podem e devem ser revisitadas através de novas metodologias que agora estão ao alcance dos pesquisadores. De fato, até agora, nossas hipóteses foram confirmadas. O que é mais interessante é que este trabalho deixou os dados falarem por si próprios, e justamente na observação dos mesmos foi possível, a cada etapa, conjecturar novas hipóteses.

\section{Referências bibliográficas}

AUSTIN, L. J. How to do things with words. Oxford: Oxford University Press, 1962.

BAGNO, M. Gramática pedagógica do português brasileira. São Paulo: Parábola Editorial, 2011.

BARBOSA, P. A. Semi-automatic and automatic tools for generating prosodic descriptors for prosody research, Proceedings from TRASP 2013, Tools and Resources for the Analysis of Speech Prosody, August 30, 2013 Laboratoire Parole et Langage, Editors: Brigitte Bigi, Daniel Hirst, Aix-en-Provence, France, 2013, pp. 86-90.

- Revelar a Estrutura Rítmica de uma língua construindo máquinas falantes: pela integração entre ciência e tecnologia de fala. In: Estudos de Prosódia, edited by Scarpa, Ester, 21-52. Campinas: Editora da Unicamp, 1999.

Measuring speech rhythm variation in a model-based framework. In: Proceedings of Interspeech 2009 - Speech and Intelligence.Londres: Causal Productions, 2009, p. 1527 - 1530.

BECHARA, E. Moderna gramática portuguesa. São Paulo: Companhia Editora Nacional, 1982.

BERBER SARDINHA, T. Lingüística de corpus. Barueri: Manole, 2004.

BIBER, D. Variation across Speech and Writing. Cambridge: Cambridge University Press, 1988.

DOI: http://dx.doi.org/10.1017/CBO9780511621024 
Representativeness in Corpus Design in Literary and Linguistic Computing, Vol. 8, n. 4, 1993. Oxford University Press, 1993.

BOERSMA, P.; WEENINK, D. Praat: doing phonetics by computer [Computer program].Version 5.3.51, retrieved 2 June 2013 from http://www.praat.org/

CARDINALETTI, A.; STARKE, M. The typology of structural deficiency: On the three grammatical classes. In: RIEMSDIJK, H. (ed.) Clitics in the Languages of Europe, Empirical Approaches to Language Typology. Berlin: Mouton de Gruyter, 1999.

CASTILHO, A. T. Nova gramática do português brasileiro. São Paulo: Contexto, 2010.

CIRÍACO, L.; VITRAL, L.; REIS, C. Intensidade e duração de formas reduzidas do Português Brasileiro. In: Revista de Estudos da Linguagem, v. 12, n. 2, 2004.

CONOVER W. J. Practical Nonparametric Statistics. 2nd ed. John Wiley, New York. 494 pp., 1980.

CRESTI E., MONEGLIA M. (a cura di), C-Oral-Rom. Integrated Reference Corpora for Spoken Romance Languages, Benjamins, Amsterdam, 2005.

CRESTI, E. \& GRAMIGNI, P. Per una linguistica corpus based dell'italiano parlato: Le unità di riferimento. In: ALBANO LEONI F., CUTUGNO F., PETTORINO M., SAVY R. (Eds.), Atti del Convegno Nazionale "Il Parlato Italiano", CD-ROM (pp. 1-26). Napoli: M. D’Auria, 2004.

DUARTE, M. E. L. Variação e Sintaxe: Clítico Acusativo, Pronome Lexical e Categoria Vazia no Português do Brasil. Dissertação de Mestrado, Pontifícia Universidade Catótila-São Paulo, 1986.

DUBOIS, J. W. et al. Santa Barbara corpus of spoken American English - Part 1. Linguistic Data Consortium, 2000.

FIGUeiredo Silva, M. C. A Posição do Sujeito no Português Brasileiro. Campinas, SP: Editora da Unicamp, 1996.

FIRENZUOLI, V.; SIGNORINI, S. LIRENZUOLI, V.; SIGNORINI, S. mp, 1996ileiro 1-26). In Atti delle Giornate del Gruppo di Fonetica Sperimentale - XIII, Pisa, Novembre 2002 ETS, Pisa. Atti.2003, p.1771 Gru

FISHER R. A. Statistical Methods for Research Workers (1st ed.) Oliver and Boyd, Edinburgh, Scotland. 239 pp. +6 tables, 1925.

GALVES, C. O Enfraquecimento da Concordância no Português Brasileiro. In: I. Roberts \& M. Kato (orgs.) Português Brasileiro - uma Viagem Diacrônica, Campinas, Editora da UNICAMP, 1993. 
HARY, B. H. (ed.). Corpus Linguistics and Modern Hebrew: Towards the Compilation of The Corpus of Spoken Israeli Hebrew (CoSIH). Tel Aviv: Tel Aviv University, TheChaim Rosenberg School of Jewish Studies, 2003.

HEUVEL, H. van den et al. SLR Validation: present state of affairs and prospects. In: Proceedings of the 2nd International Conference on Language Resources and Evaluation (LREC 2000). Paris: ELRA, p. 435-440. 2000. Disponível em: <http://www.lrecconf.org/proceedings//rec2000/pdf/39.pdf> Acesso em: 20 dez. 2012.

HEUVEL, H. van den et al. Validation of spoken language resources: an overview of basic aspects. In: Language Resources \&Evaluation, n. 42, p. 41-73, 2008.

KATO, M. A. \& TARALlO, F. Restrictive VS Syntax in Brazilian Portuguese; its Correlation with Invisible Clitics, and Visible Subjects, ms., trabalho apresentado em colóquio, University of Pennsylvania, University of Georgetown, 1987.

KATO, M. Strong and weak pronominals in the null subject parameter. In. Probus, 11, pp.137, 1999.

DOI: http://dx.doi.org/10.1515/prbs.1999.11.1.1

MACWhInNEY, B., The CHILDES Project: Tools for Analyzing Talk. 3rd Edition. Mahwah, NJ: Lawrence Erlbaum Associates, 2000.

MARTIN, P. WinPitch Corpus: A text-to-speech analysis and alignment tool. In: CRESTI, E; MONEGLIA, M. (Org.). C-ORAL-ROM: integrated reference corpora for spoken Romance languages. Amsterdam: John Benjamins, 2005, p. 40-51.

MELLO, H. Os corpora orais e o C-ORAL-BRASIL. In: RASO, T.; MELLO, H. (Org.). CORAL-BRASIL-I: Corpus de referência do português brasileiro falado informal. 1ed.: , 2012, v. 1, p. 31-54.

MELLO H. et al. Capítulo 4. Transcrição e segmentação prosódica do corpus C-ORALBRASIL: Critérios de implementação e validação. In: RASO T.; MELLO H. C-ORALBRASIL I. Corpus de referência do português brasileiro falado. I edição. Belo Horizonte, Editora UFMG, 2012, p. 125-176.

MELLO H.; RASO T. Para a transcrição da fala espontânea: o caso do C-ORAL-BRASIL. In: Revista Portuguesa de Humanidades, v. 13, n. 1, p. 153-178, 2009.

MELLO, H.; RASO, T. Illocution, modality, attitude: different names for different categories. In: MELLO, H.; PANUNZI, A.; RASO, T. (Ed.). Illocution, modality, attitude, information patterning and speech annotation. Firenze: FUP, 2010.

METTOUCHI, A. \& CHANARD, C. From Fieldwork to Annotated Corpora: The CorpAfroAs project. In: Cahiers de Faits de Langues $n^{\circ} 2.2010,255-265$.

METTOUCHI, A.; CAUBET, D.; VANHOVE, M.; TOSCO, M.; COMRIE, B.; IZRE'EL S. "CORPAFROAS. A corpus for spoken Afroasiatic languages: morphosyntactic and prosodic 
analysis”. In: CAMSEMUD 2007, F.M. Fales\& G.F. Grassi (eds), Padova: SARGON. 2010, pp. 177-180.

MITTMANN, M. O C-ORAL-BRASIL e o estudo da fala informal: um novo olhar sobre o Tópico no Português Brasileiro. Tese de Doutorado em Linguística, Faculdade de Letras, UFMG, 2012.

MONEGLIA M.; RASO T.; MITTMANN, M. M.; RIBEIRO MELLO, H. "Challenging the Perceptual Relevance of Prosodic Breaks in Multilingual Spontaneous Speech Corpora: CORAL-BRASIL / C-ORAL-ROM." In Prosodic Prominence Perceptual and Automatic Identification - Speech Prosody 2010 Satellite Workshop. Chicago: Université de Neuchâtel, 2010 .

MONEGLIA, M. Units of Analysis of Spontaneous Speech and Speech Variation in a Crosslinguistic Perspective. In: KAWAGUCHI, Y.; ZAIMA, S.; TAKAGAKI, T. In: Spoken Language Corpus and Linguistics Informatics, pp. 153-180, Amsterdam: Benjamins Publishing Company, ISBN: 9789027233172, 2006.

MONEGLIA, M. et al. Challenging the perceptual relevance of prosodic breaks in multilingualspontaneous speech corpora: C-ORAL-BRASIL/C-ORAL-ROM. Prosodic prominence perceptual and automatic identification. In: Proceedings of the Speech Prosody International Conference Satellite Workshop. Chicago: Université de Neuchâtel, 2010. Disponível em: <http://speechprosody2010.illinois.edu/papers/102010.pdf $>$ Acesso em: 20 dez. 2012.

MOURA NEVES, M. H. Gramática de usos do português. São Paulo: UNESP, 2000.

NASCIMENTO, I. B. Interpolação de constituintes entre “(vo)cê + verbo". In: Estudos Linguísticos, 39 (2), 2010.

OTHERO, G. A. Revisitando o status do pronome cê no português brasileiro. In: Revista de Estudos da Linguagem, v. 21, n. 1, 2013.

PERINI, M. A. Gramática do português brasileiro. São Paulo: Parábola, 2010.

PERINI, M. Modern Portuguese: A Reference Grammar. Yale University Press, 2002.

PETERSEN, C. A tripartição pronominal e o estatuto das proformas cê, ocê e você. In: DELTA vol. 24, n. 2,2008

RAMOS, J. O uso das formas você, ocê e cê no Dialeto Mineiro. In: HORA, D. (org.) Diversidade Linguística no Brasil. João Pessoa: Ideia, 1997.

RASO T.; MELLO H. C-ORAL-BRASIL I. Corpus de referência do português brasileiro falado. I edição. Belo Horizonte, Editora UFMG, 2012. 
RASO, T. O corpus C-ORAL-BRASIL. In: RASO T.; MELLO H. (Org.). In: C-ORALBRASIL I. Corpus de referência do português brasileiro falado informal. Belo Horizonte: Editora UFMG, 2012, p. 55-90.

RASO, T.; MITTMANN, M. M. Validação estatística dos critérios de segmentação da fala espontânea no corpus C-ORAL-BRASIL. In: Revista de Estudos da Linguagem, v. 17, n. 2, p. 73-91, 2009. Disponível em: <http://relin.letras.ufmg.br/revista/upload/17-2_04.pdf> Acesso em: 20 dez. 2012.

ROCHA, B. Características prosódicas do tópico em PE e o uso do pronome lembrete. Dissertação de Mestrado em Linguística, Faculdade de Letras, UFMG, 2012.

SCHIEL, F. et al. The validation of speech corpora. 2004. Disponível em: $<$ http://www.phonetik.uni-muenchen.de/forschung/BITS/TP2/Cookbook/>. Acesso em: 20 dez. 2012.

SINCLAIR, J. MCH. et al. COBUILD English Dictionary. London and Birmingham: Collins COBUILD, 1987.

VITRAL, L. A forma cê e a noção de gramaticalização. In: Revista de Estudos da Linguagem, Ano 5 (4), 1996.

VITRAL, L.; RAMOS, J. Réplica a Petersen (2008). A tripartição pronominal e o estatuto das proformas Cê, Ocê e Você. In: DELTA vol. 24, n.2, 2008.

VITRAL, L.; RAMOS, J. Gramaticalização: uma abordagem formal. Belo Horizonte: Faculdade de Letras FALE/UFMG, 2006.

Artigo recebido em: 31.08 .2013

Artigo aprovado em: 26.11.2013 